Postprint

\title{
Transdisciplinary development of a life-cycle based approach to measure and communicate waste prevention effects in local authorities
}

\author{
Petra Hutner ${ }^{\mathrm{a}}$, Christoph Helbig $^{*}$, a, Dennis Stindt ${ }^{\mathrm{a}}$, Andrea Thorenz $^{\mathrm{a}}$, Axel Tuma $^{\mathrm{a}}$ \\ *Address correspondence to: christoph.helbig@wiwi.uni-augsburg.de \\ ${ }^{a}$ : Resource Lab, Institute of Materials Resource Management, University of Augsburg, \\ Universitaetsstr. 16, 86159 Augsburg, Germany
}

Published in: Journal of Industrial Ecology 22 (2018) 1050-1065/https://doi.org/10.1111/jiec.12781

\begin{abstract}
Although waste prevention was promoted as the first priority for all EU member states in 2008, the actual implementation of activities has thus far been hesitant. Empirical evidence indicates that the reasons for this neglect include the limited measurability of waste prevention effects and the consequential lack of awareness, motivation and incentive systems. Our research aims to quantify waste prevention and its environmental impacts and, ultimately, to motivate the efficient implementation of waste prevention concepts by a target-group-specific communication of the results.

Embedded in a transdisciplinary research setting in close cooperation with practitioners, we develop a life-cycle based approach to calculate the effects of waste prevention in local authorities. This approach features an activity-based analysis that facilitates the assessment of both reduction of waste generated and the related environmental effects. The methodology of Life Cycle Assessment, used to calculate environmental impacts, is adapted to the specific requirements and constitutes an essential step in our measurement approach.

Finally, we demonstrate the application of this approach. Five activities deriving from real-world case studies are assessed. These case studies simulate the implementation of waste prevention in a midsized German city. We are able to reveal potential waste reduction of $74 \%$ and potential reduction of other environmental impacts ranging from $28 \%$ to $62 \%$ of the targeted material streams.
\end{abstract}

\section{Keywords}

Waste prevention, activity-based analysis, transdisciplinary, LCA, Dematerialization, Local Authorities 


\section{Introduction}

With growing pressure, the need to reduce environmental impacts of human behavior attracts the attention of politics, industry and science (European Commission 2012; OECD 2000). Among the many eco- or anthropocentric concepts advanced to reach this goal, the Circular Economy has gained momentum (Sauvé et al. 2016). A Circular Economy aims at closing the flows of materials, thus reducing the need for primary resources and simultaneously reducing waste output (Andersen 2007; Haas et al. 2015). The growing popularity of this approach reflects concerns about the pressure of economic growth, the subsequent increased resource depletion and the perceived ineffectiveness of existing sustainability concepts (Hobson 2016; Tukker 2015).

The EU adopted a Circular Economy action plan as a part of the European flagship initiative towards resource efficiency (European Commission 2016). The Ellen MacArthur Foundation (2015) proposes a framework to support responsible actors, especially policymakers, in order to enable this transition, for which a great potential for waste prevention is revealed (Ellen MacArthur Foundation 2015; Eurostat 2016a, 2016b).

In general, two different types of waste prevention can be distinguished: The reduction of waste generated and the reduction of the impacts of waste generation on humans and the environment, e.g., reducing the hazardous content of waste (European Commission 2012). This prevention should occur before, during and after use. Pre-use, reduction at source can minimize material input in both mass and content of harmful substances. The intensification of use with sharing economy concepts can prevent waste during the use phase. Post-use, a prolongation of life leads to a longer period of product circulation and can be achieved by repairing and re-using goods (Hutner et al. 2017).

Waste prevention was promoted as the first priority for all EU member states in 2008 (European Parliament and Council), and it is argued that it should dominate over recycling (Allwood 2014). However, the implementation status of waste prevention activities remains low, as is frequently stated in literature (Gentil et al. 2011; Melanen et al. 2002; Wilts et al. 2013; Wilts 2012a; Zorpas et al. 2014). Reasons include, but are not limited to, the absence of valid measurement tools for waste prevention and the resulting lack of awareness, acceptance and incentives. Together, these barriers lead to a failure to take action towards waste prevention. The results of an empirical study in local authorities suggest that these obstacles can be overcome by quantifying the positive impacts of waste prevention on the environment and society (Hutner et al. 2017). Furthermore, with proper measurement of waste prevention effects, it is possible to define benchmarks, to provide incentive systems and to establish controlling mechanisms. Combined with suitable illustration and communication, such efforts can increase the motivation and willingness of stakeholders to act.

In Germany, local authorities are among the key actors towards waste prevention. Local authorities are not only charged with waste management, but also specifically asked to prepare waste prevention concepts by the Waste Prevention Programme of the German Government (BMU 2013). In addition, they hold considerable market power accounting for $60 \%$ of all public expanses in Germany in 2006 (McKinsey \& Company 2008). This power, combined with their range of responsibilities, including construction, transportation, and environmental planning as well as legislative and administrative tasks, gives them the ability to influence waste prevention at various stages and levels, as described in Hutner et al. (2017). 
Within this article, we develop an approach to raise awareness and motivate action towards waste prevention in local authorities in Germany. The two research questions can therefore be framed as follows:

- Q1: How can the effects of waste prevention be measured, taking into account both reduction of waste generated and related environmental effects?

- Q2: In which way(s) can the results be communicated to motivate the implementation of waste prevention activities?

To address these research questions, we scrutinize existing literature and, based on the results, follow a structured process to develop a measurement approach. This measurement approach is then presented, followed by an application and a validation of our approach in local authorities in Germany. Within the discussion, we match the application process to our research aim and reflect on advantages and shortcomings.

\section{State of the art and research gap}

Analyzing the literature on measuring waste prevention, some major deficits of existing approaches are revealed. Measuring waste prevention implies the quantification of something that is nonexistent, making direct measurement, for example by weighing or counting, impossible. The approach therefore has to be indirect, necessitating a comparison with the amount of waste that would have been generated without waste prevention (Sharp et al. 2010a). Consequently, measuring the related environmental effects also includes the comparison of impacts with and without waste prevention.

Attempts at measuring waste prevention include both statistical and activity- based approaches. Statistical approaches typically aim to measure the reduction of waste generated by using existing waste data. These data are then compared with modelled values to deduce how much waste has been or can be prevented. The modelling can be either a forecast or a retrospective analysis and is usually based on factors such as production (Bruvoll and lbenholt 1997) and income (Mazzanti and Zoboli 2008). The difference between real and modelled values is credited to waste prevention. However, it is argued that decreasing amounts of waste do not automatically imply successful waste prevention; rather, they may reflect changes in economic activity (Wilts and Rademacher 2014). Additional influence factors that further complicate this approach include consumption patterns and household size as well as the time lag between the implementation of waste prevention activities and their effects. Reduction of waste generated, therefore, cannot be documented using solely statistical data (Statistisches Bundesamt 2018; Sharp et al. 2010a; Wilts and Rademacher 2014).

Activity-based approaches measure results at a micro level by actually gauging small-scale waste prevention. This measurement can be achieved by weighing, counting, timing or metering the amount of prevented waste associated with specific activities. The possible scope of application ranges from single activities to whole institutions or geographical areas (Tasaki and Yamakawa 2011; Salhofer et al. 2008; Sharp et al. 2010b; Wilts et al. 2013). While most activity-based approaches focus on reduction of waste generated (Wilts 2012b), some studies account for environmental impacts as well, applying Life Cycle Assessment (LCA) or related methodologies LCA is a tool to assess the environmental impacts of a product or service over all its life cycle stages, from raw material extraction, production, and distribution to use and, eventually, end-of-life. Aside from the amount of waste, Nessi, Rigamonti, and Grosso (2012) use cumulative energy demand (CED), global warming 
potential (GWP), abiotic resource depletion and eutrophication as impact categories for evaluating waste prevention, and expand their focus to 13 midpoint categories two years later (Nessi et al. 2014). Salemdeeb et al. (2017) analyze the prevention of food waste and focus on the greenhouse gas emissions as an environmental impact category, while Mirabella, Rigamonti, and Scalbi (2013) apply all IMPACT2002+ indicators in an LCA study that addresses dematerialization and thus covers waste prevention as a side effect.

Other than in those studies, LCA is rarely used to evaluate waste prevention; the reasons include various difficulties concerning the lack of operational methodology (Laurent et al. 2014) as well as the definition of the functional unit, if waste prevention is to be compared with waste management (Gentil et al. 2011). Waste prevention alters the functional unit, if that is based on mass. This may be solved by modelling the prevented quantity as a virtual flow (without environmental burden and no transformation in the waste management system) or by adjusting the functional unit. Detailed information on these possibilities is presented by Gentil, Gallo, and Christensen (2011) and Ekvall et al. (2007). The limited availability of data is a hindrance as well; in particular, there is little information about the environmental performance of waste prevention and the calculation of the amount of prevented waste (Gentil et al. 2011). In contrast to existing attempts, a measurement approach that addresses these two aspects is needed.

Further attempts at measuring waste prevention include hybrids of the presented procedures as well as other approaches, partially for specific waste streams or target groups. Laner and Rechberger (2009) propose an evaluation of environmental benefits by subtracting the environmental burdens before and after the implementation of waste prevention activities on the level of small and medium-sized enterprises. The burdens and, subsequently, the benefits are expressed using the CED, GWP and acidification potential. Even though taking into account environmental effects, the problem of calculating the amount of prevented waste from statistical data, including some data with poor quality, is not solved (Laner and Rechberger 2009). Sharp, Giorgi, and Wilson (2010a) introduce, among other methods, self-weighing, monitoring or reporting on a household level as well as attitude surveys to measure the reduction of waste generated, but they conclude that holistic approaches are time consuming and expensive. In Japan, payment data are analyzed to estimate waste prevention achieved through purchase of refill containers (Tasaki and Yamakawa 2011), but this approach is practical only in retail and for a very specific set of material streams. A broader view is promised by the Zero Waste Index (ZWI), which is a tool to evaluate the replacement of virgin materials with secondary resources. However, as the scope of this approach includes recycling, it is unusable for measuring waste prevention (Zaman 2014). With most of these approaches, limited data availability and insufficient data quality are major obstacles (Zaman and Lehmann 2013; Laner and Rechberger 2009; Sharp et al. 2010a).

In summary, a measurement approach meeting the requirements of waste prevention and featuring strategies for addressing challenges described above is needed. The literature review shows that, while issues like the identification of activities, the quantification of potentials, the analysis of barriers (Hutner et al. 2017) and the assessment of effects are covered, this only happens separately and thus, out of context of a specific target group. Moreover, the present measurement approaches fall short in either the quantification of the amount of prevented waste or the assessment of environmental impacts - both of which are requirements. Data availability and data quality are key challenges. Furthermore, methodological choices for state-of-the-art environmental assessment must fit the criteria of waste prevention. To address this gap, an approach based on a life cycle 
perspective and putting waste prevention in the context of a target group is necessary in order to enable and motivate action.

\section{Methodology}

The development process for the methodology can be divided into three subsequent research phases as displayed in figure 1 and is accompanied by a transdisciplinary steering board. Transdisciplinarity, extending interdisciplinarity, goes beyond the borders of academia and includes stakeholders, target groups and practitioners into the research process in order to solve complex real-world problems. Therefore, the board consists of specialists from academia representing the disciplines of resource strategy, environmental sciences, chemistry and economics, as well as representatives of the target group, and participating practitioners who specialize in resource management, waste management and administration. Throughout the research process, their role includes the identification of problems and strategies and consensus building concerning both adequacy and practicability. The instruments ensuring an integrative transdisciplinary knowledge generation include the steering board itself, workshops with practitioners, interviews, and questionnaires and thus, cover almost all levels of transdisciplinary participation (Stauffacher et al. 2008). For a detailed account, please see the Supporting Information (SI 1).

The first phase to developing a measurement approach involves obtaining knowledge of existing approaches. We therefore conduct a literature research including scientific articles, waste prevention studies and programs, and projects of different stakeholders and interest groups. The results of an empirical study covering 386 local authorities in Bavaria, Germany, complemented this information (Hutner et al. 2017). The findings were analyzed, evaluated and categorized according to their approach, advantages and drawbacks. The result of this first phase is a pool of existing measurement approaches with detailed information, which is presented in the State of the Art section. The results confirm the lack of a measurement approach combining quantification of reduction of waste generated and likely environmental benefits and identifies various shortcomings of existing approaches.

From the results gathered in the first phase, we establish criteria the measurement and communication approach has to meet. These criteria are as follows:

1. Capability to measure waste reduction and impact reduction

2. Verisimilitude (closeness to reality)

3. Communicability of results

4. Ease of use

As described above, a proper calculation of the amount of prevented waste is a basic requirement. The second issue is the assessment of associated environmental impacts. The calculation of prevented waste is crucial, as it forms the basis for the environmental assessment. The environmental assessment requires further data, for example, about the composition of prevented waste. Verisimilitude encompasses both the selection and appropriate modelling of activities, which are applicable within the target group. Because one of the main reasons for the development of this approach is to raise awareness and motivation among stakeholders, the communicability of the results is crucial. Thus, a balance between the complexity of reality and the simplicity of onedimensional results is necessary. Finally, the ease of use is a main factor in the actual application of our approach. While criteria 1 is a necessity repeatedly stated in literature, criteria 2 to 4 derive 
mostly from an empirical study within local authorities (Hutner et al. 2017) and have been discussed and agreed on by the transdisciplinary steering board.

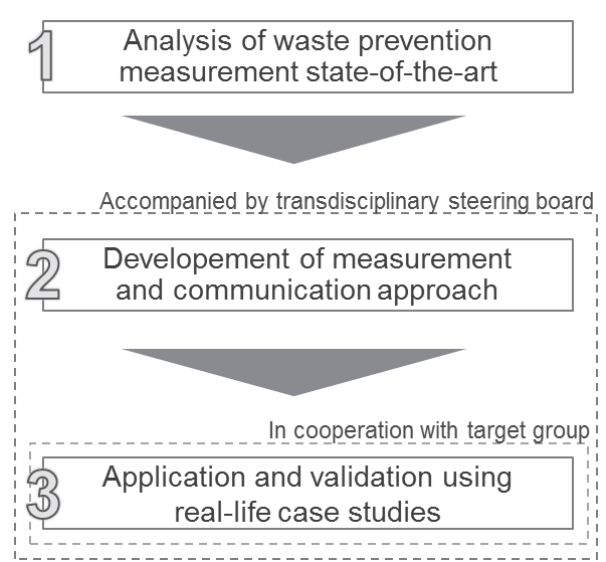

Figure 1: Methodology to develop measurement approach.

In phase 2, we develop the measurement and communication approach. The interaction with the transdisciplinary steering board is part of this phase. Existing methods, tools and approaches to measure waste prevention, assembled in phase 1 , are compiled and discussed with experts in several workshops with respect to the established criteria. With this information, we create a generic approach that incorporates an adaptation of the most suitable methods and new approaches specifically designed for waste prevention.

The third phase of this research encompasses the validation of the approach developed. For this purpose, we apply the measurement approach to real-life case studies. The case studies are selected in cooperation with our target group and derive from the day-to-day business of public administration tasks within local authorities.

\section{Measurement approach for waste prevention}

We propose the following measurement approach featuring three steps to measure waste prevention and communicate the results (see figure 2). Building on the results of the literature review, we use an activity-based approach, thus enabling not only a measurement of reduction of waste generated and the related environmental effects, but also the assessment of specific activities. Accordingly, the approach starts with the identification of activities, the subsequent quantification and assessment of their waste prevention effects and the interpretation and communication of results. 


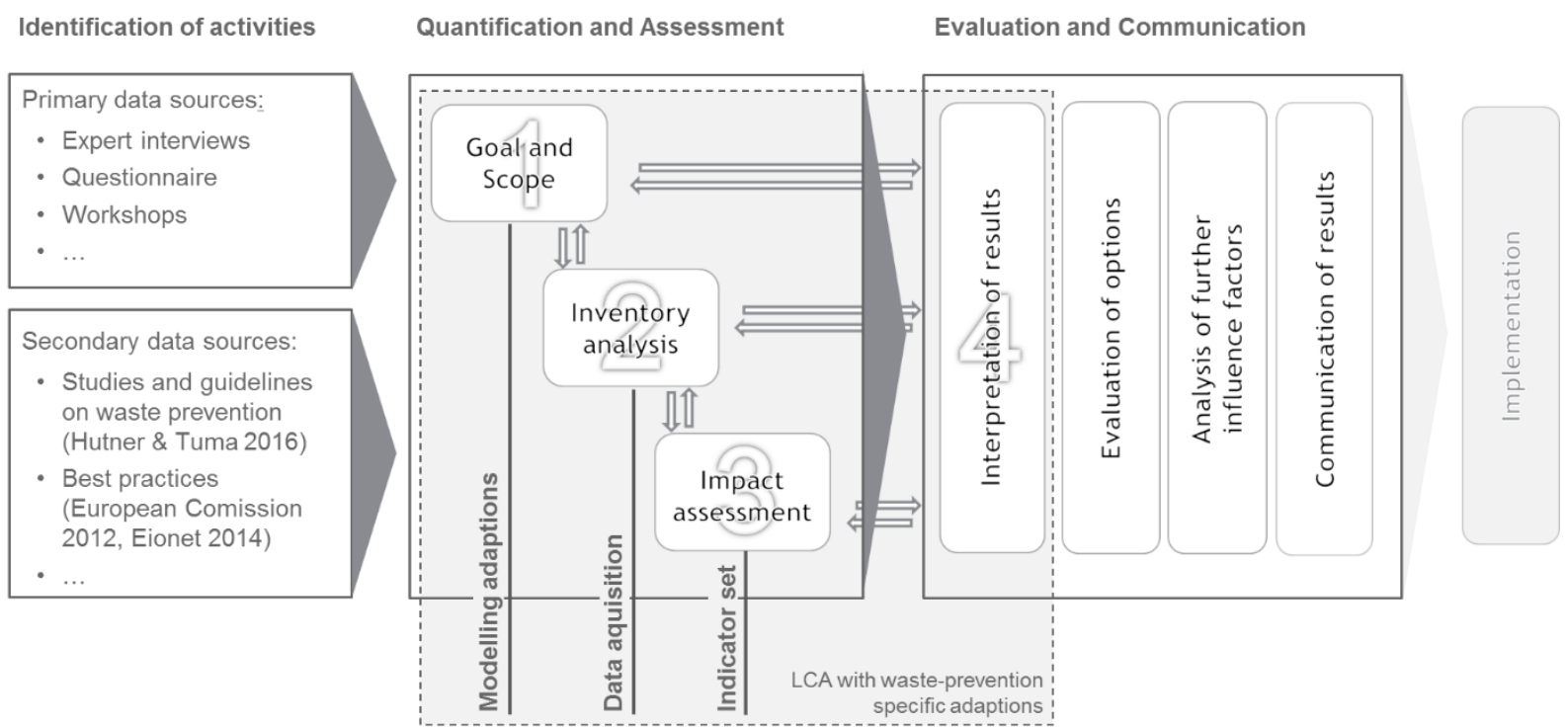

Figure 2: Measurement approach for waste prevention.

According to our assessment of the literature, the Identification of possible waste prevention activities can be accomplished by primary data collection or the use of secondary data sources. Primary data collection should focus on the target group and include tools such as expert interviews, questionnaires or topic-specific workshops. Secondary data sources include studies and guidelines on waste prevention as well as international and inter-sectoral compilations of best practices. The identification process includes four items and should be structured as follows: First, the status quo of waste prevention (e.g. existing activities, regulations etc.) is evaluated to recognize potentials, the second research item. Barriers as a third research item reveal obstacles for waste prevention. Subsequently, suitable activities to exploit this potential and overcome the barriers are identified. To improve data quality and applicability, this is best achieved in close cooperation with practitioners. Finally, the basic function of these activities and possible options to fulfill this function are defined and validated.

Quantification and Assessment form the second step of the measurement process. The primary goal of this step is the quantification of waste prevention effects for different activities by comparing the identified options to provide the functional unit against a baseline scenario (the status quo). With this, we estimate and communicate the positive impact waste prevention can achieve and identify the option with the largest environmental benefits. The state of the art approach to assess environmental impacts is LCA. We therefore apply LCA methodology based on ISO standards 14040 and 14044 (ISO 2006a, 2006b) and adopt several methodological choices to fit the domain of waste prevention. The following sections describe these adaptations within the LCA phases of Goal and Scope Definition, Life Cycle Inventory (LCI) and Life Cycle Impact Assessment (LCIA).

1. Modelling adaptations within Goal and Scope definition: The goal of this study is to provide information about the environmental performance of waste prevention activities. The focus of LCA in this context is the assessment of waste prevention to analyze whether and under which conditions specific waste prevention activities actually hold potential for reducing the environmental impacts of human consumption. In line with the guidelines provided by the International Reference Life Cycle Data System (European Commission 2010a), the intended application is policy information, and interactions with other systems are not accounted for. To assess all environmental impacts of waste prevention, the system boundaries encompass 
the product life phases from the supply of resources to production and use. Impacts arising from the end-of-life are not considered because legally, waste prevention can only take place before a product, substance or material actually becomes waste (The European Parliament and the Council of European Union 2008). We choose functional units based on the underlying function for each case study. The different options to fulfill this function (resulting from the identification phase) are modelled and compared to the baseline scenario. As these options form the basis for the next phase of quantification and assessment, they must be assessed in as much detail as possible.

2. Data acquisition for the inventory: Ideally, the detailed modelling of lifecycle processes such as material quantities, lifetimes, transport distances etc. should mostly rely on specific data from primary sources. This step may include a data acquisition process within the institution that implements the measurement approach as well as inquiries at producers and distributors. In practice, data acquisition can start simultaneously with the Identification phase of the measurement approach (within the expert interviews). Generic data from the literature and LCA databases such as ecoinvent as well as estimated values complement the specific data. For reasons of practicability and communicability and with respect to the target group, we choose attributional modelling to assess the interdependencies and potential physical flows of all relevant options and model multifunctional processes with mass allocation (Klöpffer and Grahl 2009; Finnveden et al. 2009; European Commission 2010a).

3. Indicator set to assess environmental impacts: The indicators for the measurement of waste prevention must be familiar and tangible to ensure the communicability of results (criteria 3 ). Thus, well-known impact categories at midpoint level are selected, and their number is kept to five. We choose indicators that emerge from the European Waste Framework Directive (WFD) (The European Parliament and the Council of European Union 2008) and its definition of waste prevention. According to this directive, waste prevention reduces the quantity of waste, the adverse impacts of the generated waste on the environment and human health and the content of harmful substances. A short description of each indicator to reflect this definition is displayed in figure 3. The impact categories are Waste Generation (Waste) as a proxy for the quantity of waste, representative of the impacts on the environment; Global Warming Potential (GWP), Water Depletion (WD), and Metal Depletion (MD) to include negative impacts on the atmo-, hydro- and lithosphere as vital parts of the ecosphere; and finally Human Toxicity (HTox). These indicators qualify as well-known because of a wide media coverage concerning topics like climate change, critical metals and water scarcity. We used the ReCiPe v1.10 midpoint method for classification and characterization (Goedkoop et al. 2009) of all indicators except Waste, as it is expressed in mass units. 


\begin{tabular}{|c|c|c|c|}
\hline Waste prevention reduces ${ }^{*} \ldots$ & Indicator & Unit & Description \\
\hline $\begin{array}{l}\text { the quantity } \\
\text { of waste, }\end{array}$ & $\begin{array}{l}\text { Waste Generation } \\
\text { (Waste) }\end{array}$ & $\mathrm{kg}$ or $\mathrm{t}$ & $\begin{array}{l}\text { Waste Generation is calculated by the mass of the materials } \\
\text { discarded at the End-of-Life of the goods needed to fulfill the basic } \\
\text { function (functional unit). }\end{array}$ \\
\hline \multirow{3}{*}{$\begin{array}{l}\text { the adverse impacts } \\
\text { on the environment } \\
\text { and human health or }\end{array}$} & $\begin{array}{l}\text { Global Warming } \\
\text { Potential (GWP) }\end{array}$ & $\mathrm{kg} \mathrm{CO}{ }_{2}$ eq. & \multirow{3}{*}{$\begin{array}{l}\text { The GWP reflects the impact on the atmosphere and is one of the } \\
\text { best known and best documented indicators for environmental } \\
\text { performance (Klöpffer and Grahl 2009). It summarizes the } \\
\text { cumulative greenhouse gas emissions over the product life cycle. } \\
\text { Water is a life-enabling substance. Thus, its usage represents a } \\
\text { special kind of abiotic resource depletion. The water depletion } \\
\text { counts as a widely known environmental indicator. } \\
\text { The Mineral Resource Depletion evaluates the use of primary } \\
\text { resources, some of them critical for technological progress and the } \\
\text { maintaining of certain life styles and consumption patterns. }\end{array}$} \\
\hline & $\begin{array}{l}\text { Water Depletion } \\
\text { (WD) }\end{array}$ & $\mathrm{m}^{3}$ & \\
\hline & $\begin{array}{l}\text { Metal Depletion } \\
\text { (MD) }\end{array}$ & kg Fe eq. & \\
\hline $\begin{array}{l}\text { the content of harmful } \\
\text { substances in materials } \\
\text { and products }\end{array}$ & $\begin{array}{l}\text { Human Toxicity } \\
\text { (Htox) }\end{array}$ & kg 1,4-DB eq. & $\begin{array}{l}\text { Toxicity Indicators account for the persistence and accumulation of } \\
\text { toxic chemicals. HTox measures represents the content of harmful } \\
\text { substances in products. }\end{array}$ \\
\hline
\end{tabular}

Figure 3: Selection of environmental impact categories.

The third step of our approach, the Interpretation and Communication, interprets and presents the results in a way that motivates the target group to act, e.g., by scaling the results or by addressing potential barriers. This step includes several elements to interpret, analyze, compare and interpret the assessed options in different contexts. One of these elements is the interpretation of results in accordance with the last phase of the LCA methodology. The interpretation includes testing the soundness and robustness of the former LCA phases using uncertainty and sensitivity analyses (de Bruijn et al. 2002; European Commission 2010b). On a meta level, the interpretation in this approach also puts the results in context with the overall research goal and the target group. For some activities and options, additional influencing factors may be of importance as well, such as possible investment, operational costs or simplification of processes. Afterwards, the preparation of communication material should be specific to the target group and may include booklets, information flyers, presentations, workshops or seminars. This approach addresses all criteria expressed in the Methodology section. The activity-based approach facilitates the direct measurement of waste prevented by a specific activity and consequently the measurement of associated environmental impacts (criteria 1). The integration of practitioners helps to increase the verisimilitude (criteria 2), especially concerning the identification of activities and the description of baseline scenarios, case studies, and options. Presenting the results using five tangible indicators illustrates the complexity of reality without compromising communicability (criteria 3). Furthermore, these indicators relate to the definition of waste prevention, which we argue makes them adequate for the case. Finally, ease of use is ensured by structuring our measurement approach in three distinct steps and by incorporating well-known and applicable tools into the setting (criteria 4). Even though the impact assessment with LCA assumes a static system and does not account for possible rebound or spillover effects, the results are still in line with the research goal, which is to provide information in order to raise awareness and motivation.

\section{Application of proposed methodology}

We validate our measurement approach by applying it to local authorities in Bavaria, Germany. The following sections describe the steps of our approach and relevant information concerning the case studies. The Quantification and Assessment step analyzes each of the case studies separately. Within 
the Interpretation and Communication, we demonstrate the overall reduction potential and its environmental impacts for a mid-sized German city.

\subsection{Identification}

The Identification process first establishes a knowledge base on the status quo and potentials of waste prevention within the target group. Primary data acquisition is conducted via 33 personal interviews, a questionnaire addressing 386 local authorities and a finalizing workshop. Secondary data sources include guidelines (European Commission 2012; BMU 2013), best practice compilations (EEA 2014; WRAP 2011) and scientific literature (Kopytziok 2011; Wilts and Rademacher 2014; Lebersorger and Schneider 2014; Sharp et al. 2010b). The results of this research in term of the four research items (status quo, potentials, barriers, and activities) highlights that in local authorities, the implementation status is low. The perception of potentials varies for different waste streams, but is mostly low as well. This is especially true for activities that focus on administrative processes. Barriers include a lack of awareness and information. For a thorough analysis of the process and the results, please see Hutner, Thorenz, and Tuma (2017). Additionally, 57 possible activities were identified. Out of these and via a questionnaire, five case studies are chosen by the transdisciplinary steering board for further assessment of their potential prevention effects. These case studies are the following:

1. Equipment for electronic workstations within the administration

2. The provision of drinking water in offices and public buildings

3. The use of refillables for events

4. The implementation of specific e-government applications

5. The configuration of lighting systems

For all of these case studies, practitioners provide information to determine the functional unit and possible options to fulfill these functions in semi-structured interviews. In most cases, these options are either already implemented in the local authority or planned to be implemented in the near future. For more information about the interview partners and their professional background as well as the activities and options they provided, please see the Supporting Information (SI 2). A detailed description of the interview process is given by Hutner, Thorenz, and Tuma (2017).

To successfully prevent the waste of electrical and electronic equipment, it is suggested to dematerialize electronic workplaces by securing the necessary scope of service in administrative offices with smaller devices such as "Mini-PC" or Server- based Thin Clients (STCs) instead of Desktop Computers. Water dispensers substitute drinking water from glass or plastic bottles by preparing tap water. The preparation can include filtering, carbonation, cooling, heating, and, in some cases, energizing. Water dispensers in offices and public buildings reduce the amount of packaging waste. Public events and private events on public properties can be subject to legislative regulations concerning the type of dishes to use. These regulations are often quoted as means to prevent waste if the use of disposable dishes is prohibited (Hutner and Tuma 2016). The distribution of online forms instead of actual paper forms is commonly considered to reduce not only paper waste but also environmental impacts related to their transport. This activity is an element of the transition towards e-government. Replacing common lights for communal fairs with a long-life and energy-efficient substitute is thought to greatly reduce the waste generation and environmental impact of this particular material stream. Together with practitioners, we define the functional units and identify 
options for these case studies (Table 1). A detailed description can be found in the Supporting Information (SI 2).

Table 1: Functional units and options for the five case studies.

\begin{tabular}{|c|c|c|c|c|}
\hline & Case Study & Functional Unit & & Options \\
\hline \multirow[t]{4}{*}{1} & \multirow{4}{*}{$\begin{array}{l}\text { Electronic } \\
\text { workstations }\end{array}$} & \multirow{4}{*}{$\begin{array}{l}\text { Supply of an electronic } \\
\text { workspace for } 4 \text { years of use in a } \\
\text { public administration office }\end{array}$} & $A$ & Desktop PC \\
\hline & & & B & Laptop \\
\hline & & & C & Mini-PC \\
\hline & & & $\mathrm{D}$ & Server-based Thin Client \\
\hline \multirow[t]{4}{*}{2} & \multirow[t]{4}{*}{ Water provision } & \multirow{4}{*}{$\begin{array}{l}\text { Provision of drinking water for } 25 \\
\text { employees in a public office } \\
\text { building over } 7 \text { years }\end{array}$} & A & Glass bottles $(50 \mathrm{~km})$ \\
\hline & & & B & Glass bottles (300 km) \\
\hline & & & C & Plastic bottles \\
\hline & & & D & Water dispenser \\
\hline \multirow[t]{4}{*}{3} & \multirow[t]{4}{*}{ Refillables } & \multirow{4}{*}{$\begin{array}{l}\text { Supply of soft drinks and beer in a } \\
\text { sports stadium for } 3 \text { years in } 0.5 \\
\text { liter vessels }\end{array}$} & A & Disposable PET cups \\
\hline & & & B & Disposable PLA cups \\
\hline & & & C & Reusable PP cups (\# cycles: 41) \\
\hline & & & D & Reusable, printed PP cups (\# cycles: 6) \\
\hline \multirow[t]{5}{*}{4} & \multirow[t]{5}{*}{ E-government } & \multirow{5}{*}{$\begin{array}{l}\text { Handling forms between public } \\
\text { administration and its citizens } \\
\text { over a period of } 5 \text { years }\end{array}$} & A & $\begin{array}{l}\text { Paper forms filled in at public administration } \\
\text { offices }\end{array}$ \\
\hline & & & B & Paper forms delivered by mail \\
\hline & & & C & $\begin{array}{l}\text { Printable online forms delivered by individual } \\
\text { transport }\end{array}$ \\
\hline & & & $\mathrm{D}$ & Printable online forms delivered by mail \\
\hline & & & $\mathrm{E}$ & Online forms, digital delivery \\
\hline \multirow[t]{3}{*}{5} & \multirow[t]{3}{*}{ Lighting } & \multirow{3}{*}{$\begin{array}{l}\text { Lighting for 3,602 billion lumen } \\
\text { hours }\end{array}$} & A & Incandescent light bulb (ILB) \\
\hline & & & B & Compact fluorescent lamp (CFL) \\
\hline & & & C & Light emitting diode (LED) \\
\hline
\end{tabular}

\subsection{Quantification and Assessment}

For each of these case studies and all options separately, the environmental impacts are quantified and assessed using the adapted LCA methodology. Then, the options are put in context to the baseline scenario (options $A$ ) to calculate their potential to reduce the environmental impact. We model the different options using SimaPro 8.4. Data sources include specific data from practitioners, industry data mostly concerning product composition, and secondary data from the literature. These data sources are complemented with existing material and process data within the databases available in SimaPro, mainly ecoinvent v3.01.

In some cases, similar LCA studies already exist. However, none of them exactly fit our goal and scope requirements or used all of the indicators that we choose to reflect waste prevention. We therefore model all cases individually, incorporating some information used in previous studies (Maga et al. 2013; Nessi et al. 2012; Kauertz et al. 2010; Vercalsteren et al. 2010; Garrido and Alvarez 
del Castillo 2007; Mirabella et al. 2013). For a detailed list of all modelling choices, assumptions and data sources, please see the Supporting Information (SI 3).

Figure 4 shows the LCIA results for all 20 options. The results are presented as relative impacts compared to the maximum values of each category. The values for waste prevention are only subject to modelling decisions without additional uncertainties. The four life cycle impact categories are have some uncertainties according to the life cycle inventory calculations and characterization factors. Typically, these uncertainty ranges are lowest for the global warming potential and highest for human toxicity values. Results for alternative modelling choices are part of the sensitivity analysis in the Supporting Information (SI 3).
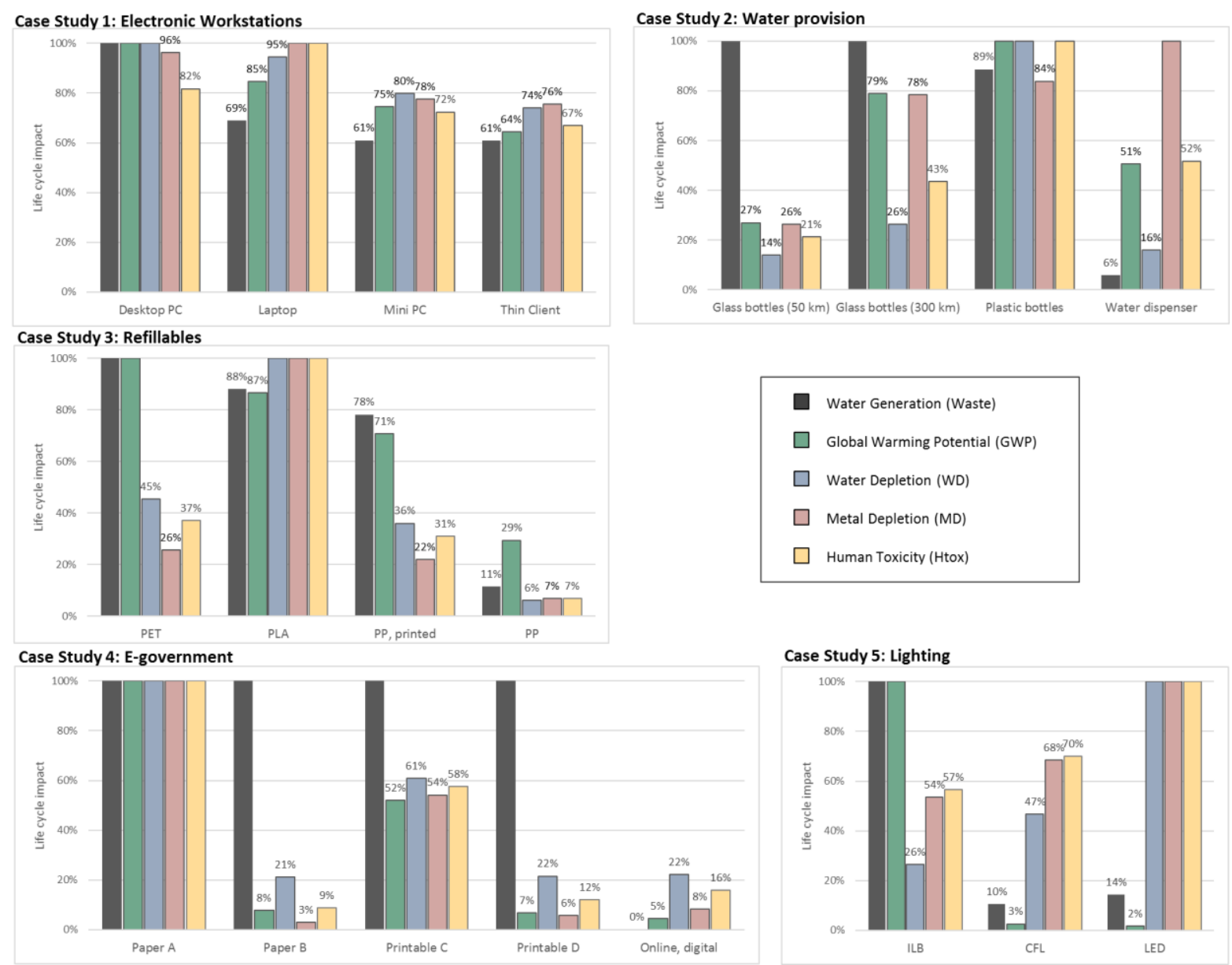

Figure 4: LCIA results for the case studies, normalized to the option (for each case study) with the highest impact for the respective indicator.

\section{Electronic workstations}

Electronic workstations in public administration offices are usually equipped with desktop computers (Koppmair and Wenger, pers. comm.). Changing this convention offers high potential to reduce environmental impacts. The environmental performance of both Mini-PCs and STCs are superior for all impact categories. Nearly $40 \%$ of waste will be prevented in these options, and the GWP is reduced by $25 \%$ if Mini-PCs are used and by $36 \%$ if STCs are used. This amounts to savings of $252 \mathrm{~kg}$ and $354 \mathrm{~kg} \mathrm{CO} 2 \mathrm{eq}$. All other indicators can be reduced by $21 \%$ to $33 \%$. The calculation of prevented waste and assessment of environmental impacts demonstrates the effectiveness of waste prevention by dematerialization. 
Water provision

The waste prevention potential of using a water dispenser to provide drinking water amounts to $1,240 \mathrm{~kg}$ of waste, which equals a $94 \%$ reduction compared to reusable glass bottles. Even single-use 1.5 liter plastic bottles with a weight of $33 \mathrm{~g}$ eventually sum to $1,170 \mathrm{~kg}$ of waste (including packaging). For all other indicators, regional bottled water with a transport distance of $50 \mathrm{~km}$ has the lowest environmental impacts. More than half of the MD and HTox impacts of the water dispenser originate from its cooling unit and its technical accessories. Due to the electricity need for its operation, the water dispenser has $75 \%$ higher impact on global warming than the base case of glass bottles.

\section{Refillables}

In terms of waste generation, reusable cups for events pose the best alternative, although they have roughly five times the weight of disposable cups. Unprinted polypropylene (PP) cups cause $11 \%$ of the category maximum of $18,100 \mathrm{~kg}$, which arises with polyethylene terephthalate (PET) cups. All other categories are at their minimum with unprinted PP cups as well. However, as event organizers sometimes choose to individualize cups for the purpose of marketing, printed cups are common. As printed cups do not have as many return cycles, the results are not as clear. While waste generation is still at least $20 \%$ lower than the maximum, WD, MD and HTox do not vary significantly from that associated with disposable PET cups. Here, the modeling choices may be decisive.

E-government

All options in which forms must be printed generate $17,500 \mathrm{~kg}$ of waste. Digital delivery drastically reduces this number to only $11.3 \mathrm{~kg}$, thus preventing $99 \%$ of waste. In particular, options with individual transport account for high $\mathrm{CO} 2$ emissions, water and resource depletion, and high toxicity. These can be reduced by delivering the forms via mail instead of personally bringing them to the public office. Delivery via mail accounts for even less MD and HTox than the use of digital forms.

\section{Lighting}

While both CFL and LED significantly reduce the quantity of waste and the GWP from $86 \%$ to $98 \%$, the WD, MD and HTox performance is inferior to that associated with conventional light bulbs. However, the life span of LEDs significantly impacts the results. We model the life span with 15,000 hours according to manufacturer information (LEDVANCE 2018), but tests demonstrate that 50,000 hours are realistic (Chang et al. 2012).

We find that for most cases that offer either an advanced technological solution or digitalization of processes, the levels of MD and HTox typically increase, while less waste and, normally, less greenhouse gas emissions are generated. This outcome can be observed with the water dispenser, the LED and, to some extent, digitally returnable forms. It is argued that in some cases of dematerialization comes at the price of higher energy demand for new production processes and the need for more critical or rare materials (Knermann et al. 2011). Our results support these statements. 


\section{Sensitivity Analyses}

Although some methodological choices within LCA must be preset for waste prevention, the modelling can still be decisive. In particular, the system boundaries and modelling assumptions influence the results. Therefore, sensitivity analyses (in the Supporting Information, SI 3) are used to verify the results (Vercalsteren et al. 2010; van der Harst et al. 2014). Smaller local authorities might have less than 100 workstations, but even with a lowered server utilization of just 20 workstations, thin clients still have the lowest impacts for the categories greenhouse gas emissions, water depletion, metal depletion and human toxicity. If two displays are modeled instead of just one, the relative waste reduction potential of mini PCs and thin clients is only reduced to $27 \%$ instead of $39 \%$. In the case of only 10 employees, for example in a smaller local authority, the water dispenser still reduces the waste generation by $88 \%$ (instead of $94 \%$ in the base case of 25 employees), but the impacts for global warming potential, metal depletion and human toxicity are the highest of all options. The consumption share of carbonated water globally is much lower than the $60 \%$ in Germany, which is assumed for the base case. If this share is as low as $20 \%$, the waste reduction potential of the water dispenser increases to $95 \%$ compared to glass bottles, because of decreased packaging material for the carbon cylinder. The impact of the refillables are highly dependent on the number of usage times for the PP cups. Unprinted PP cups remain the option with lowest impacts for all categories even if they are washed and reused only 20 times. Although using only public transportation for handing in paper forms may half the greenhouse gas emissions compared to the base case, using online forms or mail delivery still has $81 \%$ to $89 \%$ lower impacts in this category. For forms double the average length, the relative impacts from individual transport are also reduced a bit, but digital forms still have the lowest global warming potential and the waste reduction potential is even higher than in the base case. If the lighting concept of the Christmas fair is changed after 10 years and the use of any lighting material is discontinued, the waste reduction potential of LEDs is reduced from $86 \%$ to $41 \%$. Interestingly, over the period of 10 years, using CFLs would then not only have lower water and metal depletion and human toxicity impacts than the LEDs, but even result in lower greenhouse gas emissions. Overall, the sensitivity analyses show the robustness of the case study results even in case of drastic changes to the model assumptions. Detailed results of the sensitivity analyses can be found in the Supporting Information (SI 3).

\section{Interpretation and Communication of Options}

This step of the measurement approach includes the interpretation of results with regard to the research goal. The overall goal of the study is to enable and motivate local authorities to implement waste prevention concepts by measuring and visualizing the effects of waste prevention. To do so, we communicate the results on two levels. The identified activities are published in a "Guideline for the Implementation of communal waste prevention concepts" (Hutner and Tuma 2016). This addresses the lack of information we identified in the identification phase of our approach (Hutner et al. 2017). Additionally, we apply the results of the base cases of all five LCAs to a model local authority, thus presenting the possible effects in a vivid and catchy way to raise awareness and motivation for the whole target group. This model local authority is roughly based on the characteristics of the cooperating city of Augsburg, with 250,000 citizens, 6,264 employees at local authorities, 2,800 office workspaces with an average utilization of $50 \%$, a first league soccer club and a yearly Christmas market. The baseline scenario characterizes such a model local authority without 
previous waste prevention activities taken. In this baseline, we assume it uses desktop computers for all workstations, supplies drinking water for its employees by refillable glass bottles that are transported $300 \mathrm{~km}$, provides disposable cups at the soccer stadium, issues paper forms and uses incandescent light bulbs for the Christmas fair (options A, see table 1). We further assume that the option mix Waste is implemented, thus choosing the option with lowest waste generation (option mix 1 , see table 2) and that the effects will occur immediately. To model this, we use statistical data on a one-year basis rather than taking into account the time lag between the implementation of the activity and the occurrence of impacts. The quantification results of all options with a timeframe longer than one year are adapted accordingly. For example, if the desktop computer is replaced with a thin client that has an average life span of 4 years, $1 / 4$ of its environmental impacts will occur at the end of the first year. Ultimately, the yearly environmental impacts of the baseline scenario are compared with the yearly environmental impacts of the option mix 1 (Waste). The difference represents the waste prevention effects for the model community.

Table 2: Optimal choice of options for the base case depending on impact category emphasis (Scenario letter refer to options in table 1. GWP = Global Warming Potential, WD = Water Depletion, MD = Metal Depletion, HTox = Human Toxicity).

\begin{tabular}{llllllll} 
& & Baseline & \multicolumn{5}{l}{ Optimal mix of options concerning impact category } \\
\hline & Case Study & option & 1: Waste & 2: GWP & 3: WD & 4: MD & 5: HTox \\
\hline 1 & Electronic workstations & A & D & D & D & D & D \\
\hline 2 & Water provision & B & D & A & A & A & A \\
\hline 3 & Refillables & A & D & D & D & D & D \\
\hline 4 & E-government & A & E & E & B & B & B \\
\hline 5 & Lighting & A & B & C & A & A & A
\end{tabular}

Figure 5 shows that within one year, the model community could prevent $31,000 \mathrm{~kg}$ of waste if all activities are implemented. This amount translates to a waste prevention rate of $74 \%$. The GWP would be reduced by $62 \%$, and the WD, MD and HTox would decrease by $44 \%, 36 \%$ and $28 \%$, respectively. The results clearly indicate that waste prevention is feasible and environmentally preferable. 


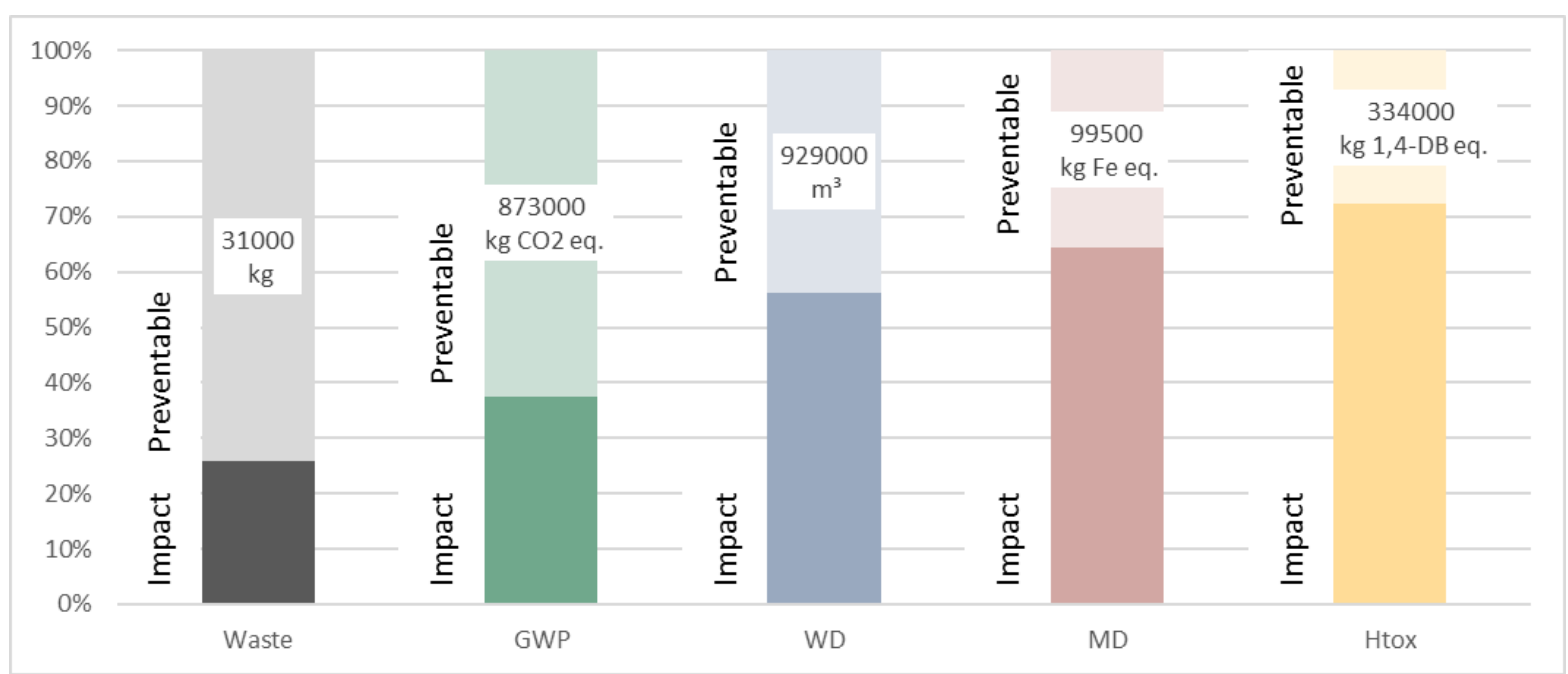

Figure 5: Waste prevention and related environmental effects for a model city. $100 \%$ equals the environmental impact of the model community with the baseline options. The Impact equals the environmental impact of the chosen waste prevention option. The difference between baseline and waste prevention option represents the waste prevention effects.

The assessed activities vary in their contribution to this overall prevention effects. Figure 6 presents the reduction potential of each option relative to the total environmental contribution. This optionbased assessment is a major component of the measurement approach, as it forms the basis for the process of selecting activities and, consequently, the actual implementation of waste prevention. 

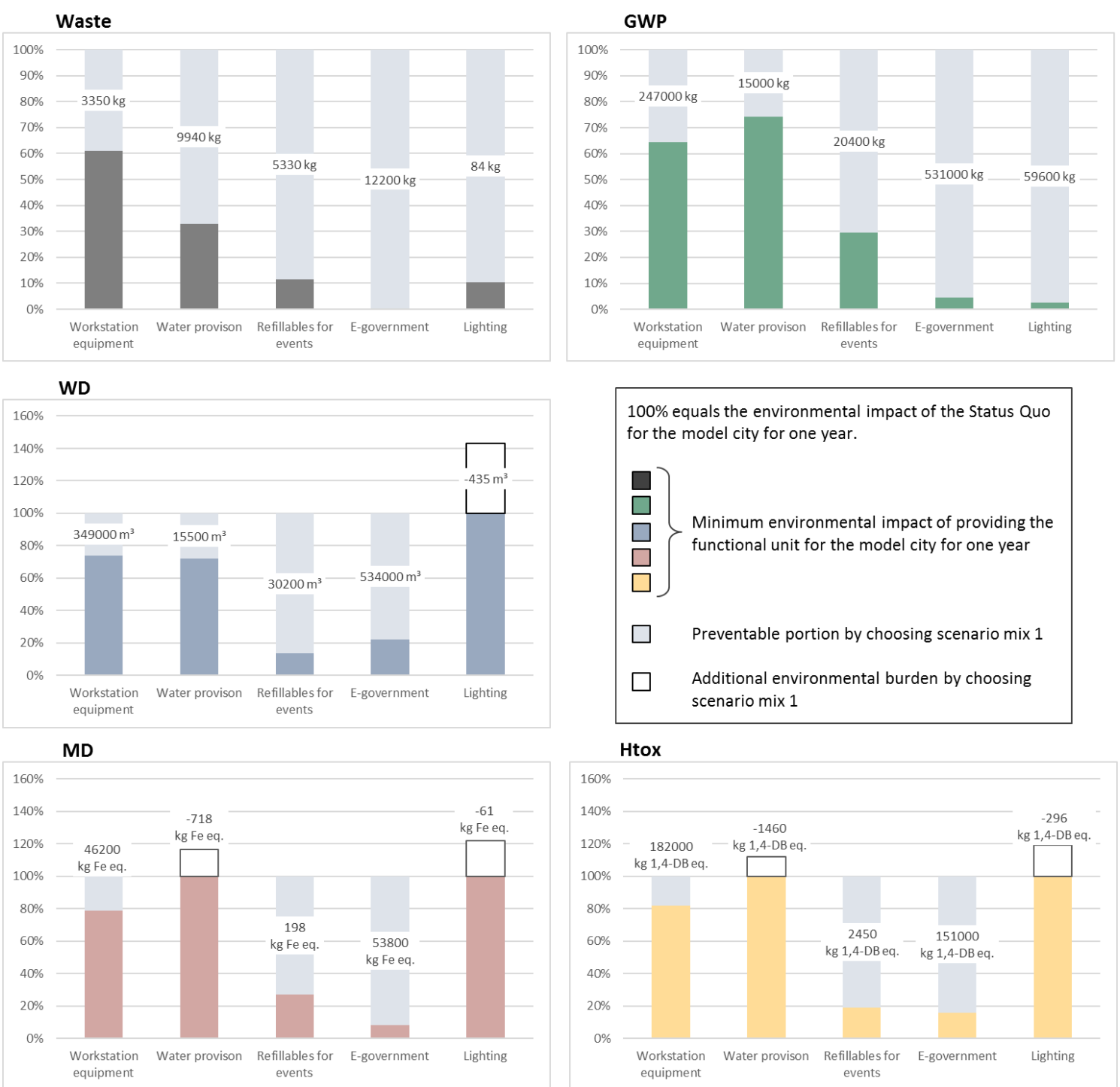

Figure 6: LCIA results for model city with option mix 1: Waste. The line at $100 \%$ depicts the environmental impact of the baseline scenario of each case study. The colored part of the bar displays the environmental impact of the chosen waste prevention option. The difference (in grey) represents the relative reduction potential. The absolute values are given to assess the overall effectiveness of each activity.

Concerning the reduction of waste quantity, the case studies show that the options for water provision and e-government are especially effective, each preventing about 10,000 kg of waste per year. The prevention potential of electronic workstations amounts to $39 \%$ of the total, corresponding to $3,400 \mathrm{~kg}$. The relative impact of the choice of lighting systems is higher (90\%), but only $84 \mathrm{~kg}$ of waste can be prevented.

E-government has the highest GWP reduction potential at more than 530,000 kg CO2 eq. per year. Although only $36 \%$ of the GWP of electronic workspaces can be prevented by the use of thin clients, this amount translates to $250,000 \mathrm{~kg} \mathrm{CO} 2 \mathrm{eq}$. Therefore, thin clients, together with e-government, are by far the most effective option for GWP reduction. The reduction potential of water provision, refillables and lighting is comparatively low, with water provision performing the worst (26\% reduction potential, $15,000 \mathrm{~kg} \mathrm{CO} 2 \mathrm{eq}$.$) .$

Similar to the GWP, the workstation equipment and digital forms show the highest potential for reducing WD. STCS decrease the WD by $26 \%$ and e-government by $78 \%$. The highest relative 
reduction is reached by the usage of unprinted PP cups (87\%). Lighting the Christmas fair with CFLs instead of the former ILBs actually requires 435 more liters of water.

Two of the activities actually increase the MD, WD or HTox. These are water provision with a water dispenser and lighting with CFLs. Combined, they account for an additional environmental burden of $780 \mathrm{~kg}$ Fe eq. and 1,760 kg 1,4-DB eq. Overall, though, a reduction in these impact categories can still be realized because option mix 1 compensates for these negative impacts. This result is mainly due to the large MD and HTox savings from thin client use and the electronic distribution of forms.

\section{Discussion and Conclusion}

The results demonstrate that the activity-based measurement is an adequate approach for measuring reduction of waste generated and the related environmental effects of waste prevention activities. We develop the measurement approach in close cooperation with practitioners by identifying essential criteria for the approach and then ensuring that these criteria are met. When applied, our measurement approach produces results on several levels: First, specific activities are identified, second, these activities are assessed. Lastly, the effects of the implementation of waste prevention by the target group are prepared for communication. The procedure allows stakeholders to choose the most fitting actions. According to their overall goals, decision makers can prioritize the five impact categories to find their optimal mix as presented in table 2, once the Quantification and Assessment phase is completed. The selected and assessed activities are then interpreted according to the size and characteristics of the target group to estimate possible overall environmental benefits. As the target group for our study are local authorities of different size and structure in Bavaria, Germany, we model a fictional city, which local authorities can relate to in general, rather than using a specific real local authority. Our set of indicators is selected in line with the definition of waste prevention in the WFD. It ensures the integration of effects that interact with ecosphere and anthroposphere as well and provides an overview of possible environmental repercussions. Additionally, the limitation on five indicators simplifies interpretation and communication.

Our approach successfully quantifies the waste prevention potentials of the model city. One of its effects is the establishment of a waste prevention concept in the German city of Augsburg, including the creation of a dedicated job for waste prevention in the city administration. The publication of a waste prevention guideline as part of the project helps identifying and implementing of waste prevention activities in other local authorities.

Nevertheless, data availability and data quality remain the key challenges in this approach. We propose to collect activity-based data in cooperation with practitioners. These data ideally cover attributes such as the functional unit, execution frequency, time horizon and, in particular, necessary products and materials as well as their characteristics. This usually needs to be complemented by using LCA databases, which can sometimes result in expenses. Additionally, known shortcomings and critical remarks for the LCA methodology must be acknowledged, since the second part of the measurement approach strongly relies on this standardized tool. However, since LCA is the state of the art, it is an essential and sensible component of our approach.

Other topics related to the LCA methodology are the selection of the modelling approach, the impact assessment method and the impact categories. In accordance with the transdisciplinary steering board and in line with our research question, we choose attributional modelling to quantify waste prevention effects and compare options. This improves the practicability of our approach for nonacademia users and reduces the uncertainty that comes with system expansion. However, it may still 
be argued that consequential modelling better reflects how markets, both primary and end-of-life, are affected by decisions towards waste prevention. Additionally, while necessary to ensure the communicability of results, the limitation to 5 indicators on midpoint-level may be subject for further discussion. Endpoint-based assessment includes more than these 5 impact categories and would have been more comprehensive. Regardless, as midpoint units are more tangible and, as confirmed by the transdisciplinary steering board, also easier to understand, we use these for this study. Summing up, as the main research goal is to motivate stakeholders within the target group to use this approach, we strongly suggest that the modelling, assessment and communication be kept as simple and transparent as possible.

The validation of our approach using real-world case studies hints at possible challenges. The sensitivity analyses of the five case studies show that overall the results are robust to altered modelling choices. However, in some cases the optimal choice of options concerning the five impact categories may change if an important modelling parameter or choice deviates strongly from the base case. Therefore, special attention must be paid to the choice of options and model parameters with the involvement of stakeholders.

The case studies also emphasize both the drawbacks and benefits of using midpoint impact categories instead of a single score. On the one hand, the results are not inevitably decisive, and there are no globally accepted characterization factors to compare $1 \mathrm{~kg}$ of $\mathrm{CO} 2 \mathrm{eq}$. with $1 \mathrm{~kg}$ of waste and $1 \mathrm{~m}^{3}$ of water to compare options. In the case of the water dispenser, the prevented waste would need to be weighed against the higher GWP and HTox, and, especially, against the MD, which is the maximum value (349 $\mathrm{kg}$ Fe eq.) for the case studies. On the other hand, the impact categories on midpoint level allow practitioners to set their own emphases according to their overall goals.

In conclusion, we argue that the advantages of our approach outweigh its limitations. The measurement process closes the existing research gap and presents the structured methodology requested by politics and practitioners alike. A commonly shared approach not only enables the comparison of waste prevention within and between different target groups but also allows viable benchmarks to be set.

Further research and future projects should aim for a database of reference activities. This would simplify the data acquisition process and improve ease of use. Although options for activities vary for different target groups, existing results may give a general idea about potential waste prevention effects. The selection of the optimal mix of activities and options is another possible area of research. To achieve this, a multi-criterial optimization algorithm can account for the challenge of weighting different impact categories. Beside the environmental impacts of waste prevention, also economic and social aspects of the activities should be taken into account in the future in order to encompass all three dimensions of sustainability. Only then, a decision whether and to which extent waste prevention contributes to sustainable resource management will be possible. For this area of further research, the issues of data availability and data quality as well as comparison and weighting between different impact categories have to be addressed.

\section{Funding}

This work was supported by the Bavarian State Ministry of the Environment and Consumer Protection as a part of the two-year research project titled "Development of a Guideline for the Preparation of Communal Waste Prevention Concepts". 


\section{References}

Allwood, J.M. 2014. Squaring the Circular Economy. In Handbook of Recycling, 445-477. Elsevier. http://linkinghub.elsevier.com/retrieve/pii/B9780123964595000301.

Andersen, M.S. 2007. An introductory note on the environmental economics of the circular economy. Sustainability Science 2(1): 133-140. http://link.springer.com/10.1007/s11625-006-0013-6.

BMU. 2013. Waste Prevention Programme of the German Government with the Involvement of the Federal Länder.

Bruijn, H. de, R. van Duin, and M.A.J. Huijbregts. 2002. Handbook on Life Cycle Assessment. Ed. by Jeroen B. Guinee, Marieke Gorree, Reinout Heijungs, Gjalt Huppes, Renée Kleijn, Arjan de Koning, Lauran van Oers, Anneke Wegener Sleeswijk, Sangwon Suh, and Helias A. Udo de Haes. Vol. 7. Eco-Efficiency in Industry and Science. Dordrecht: Springer Netherlands. http://link.springer.com/10.1007/0-306-48055-7.

Bruvoll, A. and K. Ibenholt. 1997. Future waste generation forecasts on the basis of a macroeconomic model. Resources, Conservation and Recycling 19(2): 137-149. http://linkinghub.elsevier.com/ retrieve/pii/S0921344996011895.

Chang, M.-H., D. Das, P.V. Varde, and M. Pecht. 2012. Light emitting diodes reliability review. Microelectronics Reliability 52(5): 762-782. http://linkinghub.elsevier.com/retrieve/pii/S00262 71411003283.

EEA (European Environment Agency). 2014. European Topic Centre on Sustainable Consumption and Production. Waste prevention programmes: Quantatitve targets. http://scp.eionet.europa. eu/facts/WPP/quantitative_targets. Accessed August 12, 2016.

Ekvall, T., G. Assefa, A. Björklund, O. Eriksson, and G. Finnveden. 2007. What life-cycle assessment does and does not do in assessments of waste management. Waste Management 27(8): 989996. http://linkinghub.elsevier.com/retrieve/pii/S0956053X07000724.

Ellen MacArthur Foundation. 2015. Delivering the circular economy - a toolkit for policymakers.

European Commission. 2010a. International Reference Life Cycle Data System (ILCD) handbook: General guide for Life cycle Assessment - Detailed guidance.

European Commission. 2010b. International Reference Life Cycle Data System (ILCD) handbook: Framework and requirements for Life Cycle Impact Assessment models and indicators.

European Commission. 2012. Preparing a Waste Prevention Programme: Guidance document.

European Commission. 2016. Resource Efficiency. http://ec.europa.eu/environment/resource_ efficiency/. Accessed August 18, 2016.

Eurostat. 2016a. Generation of waste by waste category. http://ec.europa.eu/environment/ resource_efficiency/. Accessed June 1, 2016.

Eurostat. 2016b. Municipal waste generation and treatment, by type of treatment method. http://ec.europa.eu/eurostat/tgm/table.do?tab=table\&init=1\&language=en\&pcode=tsdpc240\& plugin=1. Accessed June 1, 2016.

Finnveden, G., M.Z. Hauschild, T. Ekvall, J. Guinée, R. Heijungs, S. Hellweg, A. Koehler, D. Pennington, and S. Suh. 2009. Recent developments in Life Cycle Assessment. Journal of Environmental Management 91(1): 1-21. http://www.sciencedirect.com/science/article/pii/\$030147970900 2345.

Garrido, N. and M.D. Alvarez del Castillo. 2007. Environmental evaluation of single-use and reusable cups. The International Journal of Life Cycle Assessment 12(4): 252-256. http://www. springerlink.com/index/10.1065/lca2007.05.334. 
Gentil, E.C., D. Gallo, and T.H. Christensen. 2011. Environmental evaluation of municipal waste prevention. Waste Management 31(12): 2371-2379. http://linkinghub.elsevier.com/retrieve/ pii/S0956053X11003370.

Goedkoop, M.J., R. Heijung, M. Huijbregts, A. De Schryver, J. Struijs, and R. van Zelm. 2009. ReCiPe 2008, A life cycle impact assessment method which comprises harmonised category indicators at the midpoint and the endpoint level; First edition Report I: Characterisation. First Edit.

Haas, W., F. Krausmann, D. Wiedenhofer, and M. Heinz. 2015. How Circular is the Global Economy?: An Assessment of Material Flows, Waste Production, and Recycling in the European Union and the World in 2005. Journal of Industrial Ecology 19(5): 765-777. http://doi.wiley. com/10.1111/jiec.12244.

Harst, E. van der, J. Potting, and C. Kroeze. 2014. Multiple data sets and modelling choices in a comparative LCA of disposable beverage cups. Science of The Total Environment 494-495: 129143. http://linkinghub.elsevier.com/retrieve/pii/S0048969714009577.

Hobson, K. 2016. Closing the loop or squaring the circle? Locating generative spaces for the circular economy. Progress in Human Geography 40(1): 88-104. http://journals.sagepub.com/ doi/10.1177/0309132514566342.

Hutner, P., A. Thorenz, and A. Tuma. 2017. Waste prevention in communities: A comprehensive survey analyzing status quo, potentials, barriers and measures. Journal of Cleaner Production 141: 837-851. http://linkinghub.elsevier.com/retrieve/pii/S0959652616314974.

Hutner, P. and A. Tuma. 2016. Leitfaden zur Erstellung kommunaler Abfallvermeidungskonzepte.

ISO. 2006a. Umweltmanagement - Ökobilanz - Grundsätze und Rahmenbedingungen (ISO 14040:2006). Beuth Verlag GmbH.

ISO. 2006b. Umweltmanagement - Ökobilanz - Anforderungen und Anleitungen (ISO 14044:2006). Beuth Verlag $\mathrm{GmbH}$.

Kauertz, B., A. Döhner, and A. Detzel. 2010. PET Ökobilanz 2010 Ökobilanzielle Untersuchung verschiedener Verpackungssysteme für kohlensäurehaltige Mineralwässer und Erfrischungsgetränke so- wie stille Mineralwässer Endbericht PET Ökobilanz 2010 Ökobilanzielle Untersuchung verschiedener Verpackungss.

Klöpffer, W. and B. Grahl. 2009. Ökobilanz (LCA). Weinheim, Germany: Wiley-VCH Verlag GmbH \& Co. KGaA, March 11. http://doi.wiley.com/10.1002/9783527627158.

Knermann, C., M. Hiebel, A. Reinecke, D. Maga, and A. Schröder. 2011. Thin Clients 2011 Ökologische und ökonomische Aspekte virtueller Desktops.

Koppmair, W. and C. Wenger. 2013. Personal communication with P. Koppmair and C. Wenger.

Kopytziok, N. 2011. Maßnahmen zur Abfallvermeidung vor dem Hintergrund von Lebensweguntersuchungen. Müll Und Abfall 4: 152-156.

Laner, D. and H. Rechberger. 2009. Quantitative evaluation of waste prevention on the level of small and medium sized enterprises (SMEs). Waste Management 29(2): 606-613. http://linkinghub.elsevier.com/retrieve/pii/S0956053X08001761.

Laurent, A., J. Clavreul, A. Bernstad, I. Bakas, M. Niero, E. Gentil, T.H. Christensen, and M.Z. Hauschild. 2014. Review of LCA studies of solid waste management systems - Part II: Methodological guidance for a better practice. Waste Management 34(3): 589-606. http://linkinghub.elsevier.com/retrieve/pii/S0956053X13005710. 
Lebersorger, S. and F. Schneider. 2014. Food loss rates at the food retail, influencing factors and reasons as a basis for waste prevention measures. Waste Management 34(11): 1911-1919. http://linkinghub.elsevier.com/retrieve/pii/S0956053X14002694.

LEDVANCE. 2018. Parathom Classic A. https://www.ledvance.de/produkte/lampen/ledlampen/professional-led-lampen-mit-klassischen-kolbenformen/parathom-classic-a/index.jsp. Accessed April 12, 2018.

Maga, D., M. Hiebel, and C. Knermann. 2013. Comparison of two ICT solutions: desktop PC versus thin client computing. The International Journal of Life Cycle Assessment 18(4): 861-871. http://link.springer.com/10.1007/s11367-012-0499-3.

Mazzanti, M. and R. Zoboli. 2008. Waste generation, waste disposal and policy effectiveness. Resources, Conservation and Recycling 52(10): 1221-1234. http://linkinghub.elsevier.com/ retrieve/pii/S0921344908001079.

McKinsey \& Company. 2008. Potentiale der öffentlichen Beschaffung für ökologische Industriepolitik und Klimaschutz.

Melanen, M., P. Kautto, H. Saarikoski, M. Ilomäki, and H. Yli-Kauppila. 2002. Finnish waste policyeffects and effectiveness. Resources, Conservation and Recycling 35(1-2): 1-15. http://linkinghub.elsevier.com/retrieve/pii/S092134490100115X.

Mirabella, N., L. Rigamonti, and S. Scalbi. 2013. Life cycle assessment of Information and Communication Technology application: a case study of dematerialization in the Italian Public Administration. Journal of Cleaner Production 44: 115-122. http://linkinghub.elsevier.com/ retrieve/pii/S0959652612006348.

Nessi, S., L. Rigamonti, and M. Grosso. 2012. LCA of waste prevention activities: A case study for drinking water in Italy. Journal of Environmental Management 108: 73-83. http://linkinghub.elsevier.com/retrieve/pii/S0301479712002149.

Nessi, S., L. Rigamonti, and M. Grosso. 2014. Waste prevention in liquid detergent distribution: A comparison based on life cycle assessment. Science of The Total Environment 499: 373-383. http://linkinghub.elsevier.com/retrieve/pii/S0048969714011917.

OECD. 2000. Strategic Waste Prevention: OECD Reference Manual.

Salemdeeb, R., D. Font Vivanco, A. Al-Tabbaa, and E.K.H.J. zu Ermgassen. 2017. A holistic approach to the environmental evaluation of food waste prevention. Waste Management 59: 442-450. http://linkinghub.elsevier.com/retrieve/pii/S0956053X16305463.

Salhofer, S., G. Obersteiner, F. Schneider, and S. Lebersorger. 2008. Potentials for the prevention of municipal solid waste. Waste Management 28(2): 245-259. http://linkinghub.elsevier.com/ retrieve/pii/S0956053X07000542.

Sauvé, S., S. Bernard, and P. Sloan. 2016. Environmental sciences, sustainable development and circular economy: Alternative concepts for trans-disciplinary research. Environmental Development 17: 48-56. http://linkinghub.elsevier.com/retrieve/pii/S2211464515300099.

Sharp, V., S. Giorgi, and D.C. Wilson. 2010a. Methods to monitor and evaluate household waste prevention. Waste Management \& Research 28(3): 269-280. http://journals.sagepub.com/ doi/10.1177/0734242X10361508.

Sharp, V., S. Giorgi, and D.C. Wilson. 2010b. Delivery and impact of household waste prevention intervention campaigns (at the local level). Waste Management \& Research 28(3): 256-268. http://journals.sagepub.com/doi/10.1177/0734242X10361507. 
Statistisches Bundesamt. 2018. Erläuterungen zu den Umweltökonomischen Gesamtrechnungen: Erläuterungen zur Erhebung der Abfallwirtschaft. https://www.destatis.de/DE/ZahlenFakten/ GesamtwirtschaftUmwelt/Umwelt/UmweltstatistischeErhebungen/Abfallwirtschaft/Methoden/ Methoden.html. Accessed April 12, 2018.

Stauffacher, M., T. Flüeler, P. Krütli, and R.W. Scholz. 2008. Analytic and Dynamic Approach to Collaboration: A Transdisciplinary Case Study on Sustainable Landscape Development in a Swiss Prealpine Region. Systemic Practice and Action Research 21(6): 409-422. http://link.springer.com/10.1007/s11213-008-9107-7.

Tasaki, T. and H. Yamakawa. 2011. An estimation of the effectiveness of waste prevention by using point-of-sales (POS) data-The case of refills for shampoo and hair conditioner in Japan. Resources, Conservation and Recycling 57: 61-66. http://linkinghub.elsevier.com/retrieve/ pii/S0921344911001996.

The European Parliament and the Council of European Union. 2008. DIRECTIVE 2008/98/EC OF THE EUROPEAN PARLIAMENT AND OF THE COUNCIL of 19 November 2008 on waste and repealing certain Directives. Official Journal of the European Union 312: 3-30.

Tukker, A. 2015. Product services for a resource-efficient and circular economy - a review. Journal of Cleaner Production 97: 76-91. http://linkinghub.elsevier.com/retrieve/pii/S0959652613008135.

Vercalsteren, A., C. Spirinckx, and T. Geerken. 2010. Life cycle assessment and eco-efficiency analysis of drinking cups used at public events. The International Journal of Life Cycle Assessment 15(2): 221-230. http://link.springer.com/10.1007/s11367-009-0143-z.

Wilts, H. 2012a. The Ambiguous Relation Between Waste Incineration and Waste Prevention. In , 349-370. http://link.springer.com/10.1007/978-1-4471-2306-4_15.

Wilts, H. 2012b. National waste prevention programs: indicators on progress and barriers. Waste Management \& Research 30(9_suppl): 29-35. http://journals.sagepub.com/doi/10.1177/ $0734242 \times 12453612$.

Wilts, H., G. Dehoust, D. Jepsen, and F. Knappe. 2013. Eco-innovations for waste prevention - Best practices, drivers and barriers. Science of The Total Environment 461-462: 823-829. http://linkinghub.elsevier.com/retrieve/pii/S0048969713006499.

Wilts, H. and B. Rademacher. 2014. Potentials and Evaluation of Preventive Measures - A Case Study for Germany. International Journal of Waste Resources 4(1). https://www.omicsonline.com/ open-access/potentials-and-evaluation-of-preventive-measures-a-case-study-for-germany2252-5211.1000137. php?aid=23454.

WRAP. 2011. Achieving good practice Waste Minimisation and Management: Guidance for construction clients, design teams and contractors.

Zaman, A.U. 2014. Measuring waste management performance using the "Zero Waste Index": the case of Adelaide, Australia. Journal of Cleaner Production 66: 407-419. http:// linkinghub.elsevier.com/retrieve/pii/S0959652613007129.

Zaman, A.U. and S. Lehmann. 2013. The zero waste index: a performance measurement tool for waste management systems in a "zero waste city." Journal of Cleaner Production 50: 123-132. http://linkinghub.elsevier.com/retrieve/pii/S095965261200635X.

Zorpas, A.A., K. Lasasridi, C. Abeliotis, I. Voukkali, P. Loizia, A. Georgiou, C. Chroni, K. Phanou, and N. Bikaki. 2014. Waste prevention campaign regarding the Waste Framework Directive. Fresenius Environmental Bulletin 23(14a): 2876-2883. 
Postprint

\title{
Transdisciplinary development of a life-cycle based approach to measure and communicate waste prevention effects in local authorities
}

\author{
Supporting Information \\ Petra Hutner ${ }^{a}$, Christoph Helbig ${ }^{*}$,, Dennis Stindt ${ }^{a}$, Andrea Thorenz $^{a}$, Axel Tuma ${ }^{a}$ \\ *Address correspondence to: christoph.helbig@wiwi.uni-augsburg.de \\ a: Resource Lab, Institute of Materials Resource Management, University of Augsburg, \\ Universitaetsstr. 16, 86159 Augsburg, Germany
}

Supplementary Material to:

Transdisciplinary development of a life-cycle based approach to measure and communicate waste prevention effects in local authorities, Journal of Industrial Ecology 22 (2018), available at:

https://doi.org/10.1111/jiec.12781

\begin{tabular}{lccc} 
Section Topic & Tables & Figures & Page \\
\hline Transdisciplinary research setting - procedure and instruments & SI 1 & S2 \\
\hline Interview partners and selection of case studies & SI 2 & S3 \\
\hline Description and modelling details of case studies & SI 3 & SI 2-6 & S5 \\
\hline References & & S34
\end{tabular}




\section{SI 1: Transdisciplinary research setting - procedure and instruments}

The instruments of transdisciplinary research can be depicted depending on the intensity of involvement (Stauffacher et al. 2008). Figure SI 1 depicts the elements we used within this project according to the research phases.

The steering board consisting of experts and practitioners in the fields of resource strategy, environmental sciences, chemistry, economics, and communal administration accompanies and guides all research phases from the framing of research items, goal, and methodology (preparation phase) to the implementation of the approach. Workshops with different kinds of stakeholders are mostly used for the Identification of activities and the Evaluation and Communication. A two-study research design featuring personal interviews and a questionnaire provides information about activities for the Identification and Quantification. Table SI 1 presents an overview on the interview partners and the information gained in these interviews. Presentations and the publication of results are among the communication instruments on a purely informational level.

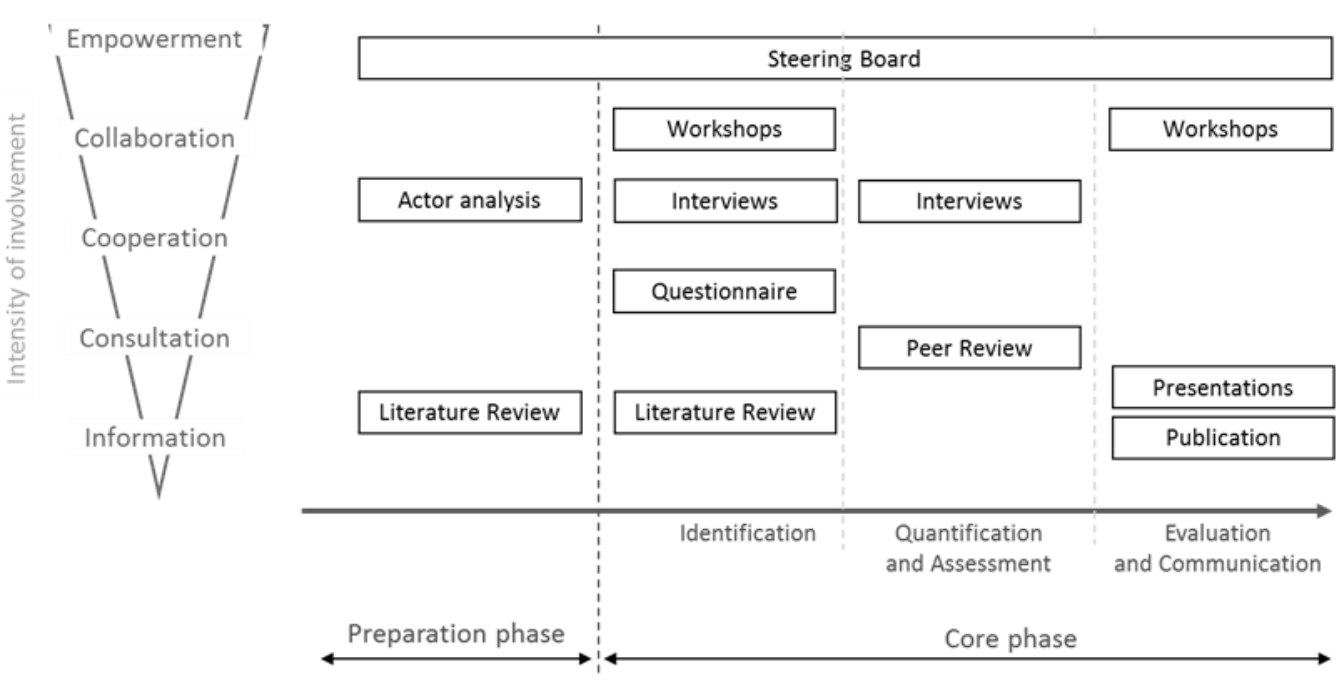

Figure SI 1: Instruments of transdiciplinary research used whithin this research project. 


\section{SI 2: Interview partners and selection of case studies}

Table SI 2: Overview on interview partners and information input

\begin{tabular}{|c|c|c|c|c|c|c|}
\hline \# & Local authority & Departement & Unit & Position & Case Study & Input for options \\
\hline 1 & Augsburg & Social & & Employee & & \\
\hline 2 & Augsburg & Construction & Civil engineering & Head of unit & & \\
\hline 3 & Augsburg & Education & Schools & Employee & & \\
\hline 4 & Augsburg & Odnungsreferat & & Employee & Case Study 5 & Option C (LED) \\
\hline 5 & Augsburg & Organisation & IT & Employee & Case Study 1 & Option C (Mini PC) \\
\hline 6 & Augsburg & Organisation & IT & Head of unit & Case Study 1 & Options A, C (Desktop PC, Mini PC) \\
\hline 7 & Augsburg & Education & Kindergardens & Employee & & \\
\hline 8 & Augsburg & Environment & Environment & Employee & Case Study 3 & Options A, B, C, D \\
\hline 9 & Augsburg & Economy & Estates & Employee & & \\
\hline 10 & Augsburg & Organisation & Main office & Employee & Case Study 4 & \\
\hline 11 & Augsburg & Cultural affairs and Sports & Public swimming pools & Employee & & \\
\hline 12 & Miesbach & Construction and Environment & Waste management & Employee & & \\
\hline 13 & Augsburg & Construction & Regulatory agency & Head of unit & Case Study 4 & \\
\hline 14 & Augsburg & Construction & Building construction & Head of unit & & \\
\hline 15 & Augsburg & Finance and $\mathrm{HR}$ & & Head of departement & Case Study 4 & \\
\hline 16 & Munich & Communal affairs & Infrastructural services & Employee & Case Study 2 & Option D (Aquatower) \\
\hline 17 & Munich & Work and Economy & Events & Employee & & \\
\hline 18 & Munich & Communal affairs & Markets & Employee & & \\
\hline 19 & Munich & Work and Economy & Events & Head of unit & Case Study 3 & Options A, D \\
\hline 20 & Munich & Work and Economy & Events & Employee & Case Study 3 & \\
\hline
\end{tabular}




\begin{tabular}{|c|c|c|c|c|c|c|}
\hline 21 & Munich & Communal affairs & Markets & Head of unit & & \\
\hline 22 & Munich & Communal affairs & Markets & Employee & & \\
\hline 23 & Munich & Communal affairs & Infrastructural services & Head of unit & & \\
\hline 24 & Augsburg & Cultural affairs and Sports & Sports infrastructure & Employee & Case Study 3 & Options A, D \\
\hline 25 & Augsburg & Cultural affairs and Sports & Sports infrastructure & Employee & & \\
\hline 26 & Munich & Environment and Health & Waste management & Employee & Case Study 2 & Options A, B, C, D \\
\hline 27 & Munich & Environment and Health & Inherited waste & Employee & & \\
\hline 28 & Munich & Organisation & Main office & Employee & & \\
\hline 29 & Munich & Organisation & Controlling & Employee & & \\
\hline 30 & Munich & Municipal enterprise & it@M & Employee & Case Study 1 & Options A, D (Desktop PC, STC) \\
\hline 31 & Munich & Municipal enterprise & it@M & Employee & Case Study 1 & Options A, D (Desktop PC, STC) \\
\hline 32 & Munich & Municipal enterprise & AWM & estellt & & \\
\hline
\end{tabular}




\section{SI 3: Description and modelling details of case studies}

\section{Case study 1: Electronic Workstations}

To successfully prevent waste of electrical and electronic equipment, it is suggested to dematerialize electronic workplaces. This can be done by securing the necessary scope of service with smaller devices such as "Mini-PC" or Server based Thin Clients (STC) instead of Desktop Computers. Administration of local authorities and schools are possible fields of application within local authorities. This case study is currently a subject of discussion in the German cities of Augsburg (option of choice: Mini PC) and Munich (option of choice: STC) (Koppmair and Wenger 2013, pers. comm.; Mairgünther and Lopes 2014, pers. comm.). A standard electronic working space consists of a workstation, display, pointing device and keyboard. With option A, the workstation is a tower. Option B and C feature a laptop or a Mini PC as workstation, while in D additionally to the thin client the proportionate server is modelled. The server supplies 100 thin clients. Additional information about the characteristics of each option is given in the Modelling details.

According to personal interviews with practitioners, electronic workstations in administrative offices of local authorities are replaced every 4 to 5 years (Koppmair and Wenger 2013, pers. comm.; Mairgünther and Lopes 2014, pers. comm.). This information affects our modelling in two ways: First, we assume that, since an exchange is inevitable, the old devices have to be discarded anyway and thus exclude the dismantling and end-of-life of existing desktop computers from our modelling. Secondly, we assume a lifetime of 4 years for the new devices, with 220 workdays per year. The usage time therefore amounts to 880 workdays. The intensity of use and energy demand differs between active, sleep and off mode. We assume that the material composition of all products variated only slightly in the last couple of years, thus allowing us to use older data where needed. This data is adjusted to current conditions by using an adaption factor based on mass (see table SI 2). We assume further that the material composition of the desktop PC and server are similar and that the server therefore also can be modelled by a factor based on weight (Maga et al. 2013).The same approach is used for Mini PC. The weights we used are average values for options $A$ and $B$ and specific product information for $C$ and D (Maga et al. 2013; Fujitsu 2014).

The first part of the following table presents the data sources (Literature, Personal communication, and LCl data) used for modelling. The second part describes the modelling characteristics of each option in detail. The numbers in brackets refer to the data sources in the first part.

Table SI 3: Adaption factors based on weight

\begin{tabular}{|c|c|c|c|c|}
\hline Option \# & Option & Average Weight & Weight in existing dataset & Adaptation factor for existing dataset \\
\hline A & Desktop PC & $6.37 \mathrm{~kg}$ & $11.3 \mathrm{~kg}$ & 0.56 \\
\hline B & Laptop & $2.57 \mathrm{~kg}$ & $3.15 \mathrm{~kg}$ & 0.82 \\
\hline C & Mini PC & $1.6 \mathrm{~kg}$ & $11.3 \mathrm{~kg}$ & 0.14 \\
\hline
\end{tabular}




\section{Case Study 1}

Literature used for modelling

\section{Reference \#}

$2 \quad$ (Fraunhofer UMSICHT 2011)

$3 \quad$ (Fujitsu 2014)

$4 \quad$ (IVF 2007)

$5 \quad$ (Maga et al. 2013)

$6 \quad$ (Stiel and Teuteberg 2013)

Personal communication used for

modelling

(Mayer 2013, pers. comm.)

(Mairgünther and Lopes 2014, pers. comm.)

(Koppmair and Wenger 2013, pers. comm.)

$\mathrm{LCl}$ data used for modelling (main processes) ecoinvent v3.01
Acrylonitrile-butadiene-styrene copolymer \{GLO\}| market for | Alloc Def, U

\begin{tabular}{|c|c|}
\hline 10 & Acrylonitrile-butadiene-styrene copolymer $\{$ GLO\}| market for | Alloc Def, U \\
\hline 11 & Capacitor, for surface-mounting $\{G L O\} \mid$ market for | Alloc Def, $U$ \\
\hline 12 & Computer, desktop, without screen $\{\mathrm{GLO}\} \mid$ production | Alloc Def, $\mathrm{U}$ \\
\hline 13 & Copper wire, technology mix, consumption mix, at plant, cross section $1 \mathrm{~mm}^{2} \mathrm{EU}-15 \mathrm{~S}$ \\
\hline 14 & Display, liquid crystal, 17 inches $\{G L O\} \mid$ production | Alloc Def, $U$ \\
\hline 15 & Electric connector, peripheral component interconnect buss $\{G L O\} \mid$ market for | Alloc Def, $U$ \\
\hline 16 & Electricity mix, AC, consumption mix, at consumer, $<1 \mathrm{kV}$ DE $S$ \\
\hline 17 & Ferrite $\{G L O\} \mid$ market for | Alloc Def, $U$ \\
\hline 18 & Folding boxboard/chipboard \{GLO\}| market for | Alloc Def, U \\
\hline 19 & Galvanized steel sheet, at plant/RNA \\
\hline 20 & Integrated circuit, memory type $\{\mathrm{GLO}\} \mid$ market for | Alloc Def, $\mathrm{U}$ \\
\hline 21 & Keyboard $\{$ GLO\}| production | Alloc Def, U \\
\hline 22 & Pointing device, optical mouse, with cable $\{$ GLO\}| production | Alloc Def, $U$ \\
\hline 23 & Printed wiring board, surface mounted, unspecified, $\mathrm{Pb}$ containing $\{\mathrm{GLO}\} \mid$ market for | Alloc Def, $\mathrm{U}$ \\
\hline 24 & Printed wiring board, surface mounted, unspecified, $\mathrm{Pb}$ free $\{\mathrm{GLO}\} \mid$ market for | Alloc Def, $\mathrm{U}$ \\
\hline
\end{tabular}


SCOPE

\begin{tabular}{|c|c|c|c|c|}
\hline Usage time, years & $4[7,9]$ & & & \\
\hline Workdays per year & 220 & & & \\
\hline Active mode, hours per day & $6.48[4]$ & & & \\
\hline Sleep mode, hours per day & $8.64[4]$ & & & \\
\hline Off mode, hours per day & $8.88[4]$ & & & \\
\hline Days of operation & 880 & & & \\
\hline Max. server utilization & $130[5]$ & & & \\
\hline Assumed server utilization & 100 & & & \\
\hline \multicolumn{5}{|l|}{ MODELING } \\
\hline & Desktop PC & Laptop & Mini PC & Thin Client (and Server) \\
\hline \multicolumn{5}{|l|}{ Quantity } \\
\hline Weight, kg & 6.37 & 2.57 & $1.6[3]$ & $2.69[5]$ \\
\hline \multicolumn{5}{|l|}{ Electricity use } \\
\hline Active, kWh per hour & $0.0782[4]$ & $0.032[4]$ & 0.0391 & $0.0115[5]$ \\
\hline Sleep, kWh per hour & $0.0022[4]$ & $0.003[4]$ & 0.0011 & $0.0019[5]$ \\
\hline Off, kWh per hour & $0.0027[4]$ & $0.0015[4]$ & 0.0014 & $0.0019[5]$ \\
\hline Overall, kWh & 468,01 & 210.82 & 234.4 & 124.56 \\
\hline \multicolumn{5}{|c|}{ EXEMPLARY BILL OF MATERIALS FOR THIN CLIENT } \\
\hline \multicolumn{5}{|l|}{ Material } \\
\hline Ferrite & & 8.3 & g & \\
\hline
\end{tabular}




\begin{tabular}{|c|c|c|}
\hline Steel, chromium steel $18 / 8$, hot rolled & 120.7 & $\mathrm{~g}$ \\
\hline Galvanized steel sheet & 785.16 & g \\
\hline Copper wire, technology mix, consumption mix & 180.6 & g \\
\hline Iron-nickel-chromium alloy & 45.3 & g \\
\hline Acrylonitrile-butadiene-styrene copolymer & 345.74 & g \\
\hline Polyethylene, low density & 11.9 & g \\
\hline Polycarbonate & 1.16 & g \\
\hline Polyurethane, flexible foam & 2 & g \\
\hline Printed wiring board, surface mounted, unspecified, $\mathrm{Pb}$ free & 120.59 & g \\
\hline Integrated circuit, memory type & 23.47 & $\mathrm{~g}$ \\
\hline Capacitor, for surface-mounting & 347.02 & g \\
\hline Solder, bar, Sn95.5Ag3.9Cu0.6, for electronics industry & 12.77 & g \\
\hline Electric connector, peripheral component interconnect buss & 96.75 & g \\
\hline Printed wiring board, mounted mainboard, desktop computer, $\mathrm{Pb}$ free & 32.17 & g \\
\hline Light emitting diode & 10.26 & g \\
\hline Folding boxboard/chipboard & 546 & g \\
\hline Graphic paper, $100 \%$ recycled & 0.13 & g \\
\hline \multicolumn{3}{|l|}{ Production } \\
\hline Electricity mix & 937 & MJ \\
\hline Process water & 384 & $\mathrm{~kg}$ \\
\hline Cooling Water & 228 & 1 \\
\hline
\end{tabular}




\section{Sensitivity Analysis 1: Electronic Workstations}

We assume two altered modelling choices for the case study of electronic workstations.

In the first sensitivity case, we assume that the thin-client system has a lower server utilization of only 20 thin-clients per server, instead of 100 . This increases the impacts of only the option D.

In the second sensitivity case, we assume that all workstations are equipped with two displays, instead of only one. This increases the impact of all options.

\begin{tabular}{|c|c|c|c|}
\hline Altered modeling parameter & Base case $(1 \mathrm{~A} 0,1 \mathrm{~B} 0,1 \mathrm{C} 0,1 \mathrm{D} 0)$ & Sensitivity case 1 ( $1 \mathrm{~A} 1,1 \mathrm{~B} 1,1 \mathrm{C} 1,1 \mathrm{D} 1)$ & Sensitivity case $2(1 \mathrm{~A} 2,1 \mathrm{~B} 2,1 \mathrm{C} 2,1 \mathrm{D} 2)$ \\
\hline Server utilization (Thin Client) & $100(1 \mathrm{DO})$ & 20 (1D0) & 100 (1D2 unchanged) \\
\hline Display, number (all options) & 1 (all options) & 1 (unchanged) & 2 (all options) \\
\hline
\end{tabular}

\section{Results sensitivity analyses electronic workstations:}

\begin{tabular}{|c|c|c|c|c|c|c|c|c|c|c|c|c|c|}
\hline Sensitivity case & & $1 \mathrm{~A} 0$ & $1 \mathrm{~B} 0$ & $1 C 0$ & 1D0 & $1 \mathrm{~A} 1$ & 1B1 & $1 C 1$ & 1D1 & $1 \mathrm{~A} 2$ & $1 \mathrm{~B} 2$ & $1 C 2$ & 1D2 \\
\hline Modelling choice & & 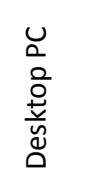 & $\begin{array}{l}0 \\
\stackrel{0}{0} \\
\frac{0}{0} \\
\frac{0}{3}\end{array}$ & $\begin{array}{l}\text { U } \\
. \overline{\underline{\Sigma}} \\
\dot{\Sigma}\end{array}$ & 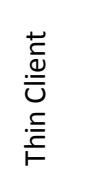 & $\begin{array}{l}\ddot{N} \\
\tilde{J} \\
心 \\
\tilde{D} \\
\infty\end{array}$ & 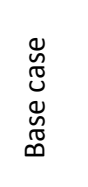 & 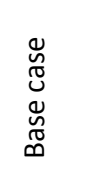 & 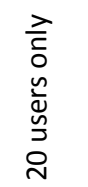 & $\begin{array}{l}\stackrel{n}{a} \\
\frac{\pi}{0} \\
. \frac{0}{0} \\
0 \\
\stackrel{3}{n}\end{array}$ & $\begin{array}{l}\stackrel{n}{a} \\
\frac{\pi}{0} \\
. \frac{n}{0} \\
0 \\
0 \\
i=\end{array}$ & $\begin{array}{l}\stackrel{n}{\lambda} \\
\frac{\pi}{0} \\
. \frac{n}{0} \\
0 \\
\vdots \\
i\end{array}$ & $\begin{array}{l}\frac{n}{\lambda} \\
\frac{\pi}{0} \\
. \frac{n}{0} \\
0 \\
0 \\
\vdots\end{array}$ \\
\hline Waste Generation (Waste) & $\mathrm{kg}$ & 12.2 & 8.4 & 7.5 & 7.4 & 12.2 & 8.4 & 7.5 & 7.6 & 17.3 & 13.5 & 12.5 & 12.5 \\
\hline Global Warming Potential (GWP) & $\mathrm{kg} \mathrm{CO}_{2}$ eq & 993 & 840 & 740 & 639 & 993 & 840 & 740 & 642 & 1478 & 1.325 & 1225 & 1.124 \\
\hline Water Depletion (WD) & $\mathrm{m}^{3}$ & 1926 & 1822 & 1538 & 1427 & 1926 & 1822 & 1538 & 1441 & 3100 & 2.996 & 2712 & 2.601 \\
\hline Metal Depletion (MD) & kg Fe eq & 308 & 320 & 249 & 242 & 308 & 320 & 249 & 246 & 473 & 485 & 414 & 407 \\
\hline Human Toxicity (Htox) & kg 1,4-DB eq & 1448 & 1771 & 1283 & 1187 & 1448 & 1771 & 1283 & 1199 & 2336 & 2.659 & 2171 & 2.075 \\
\hline
\end{tabular}




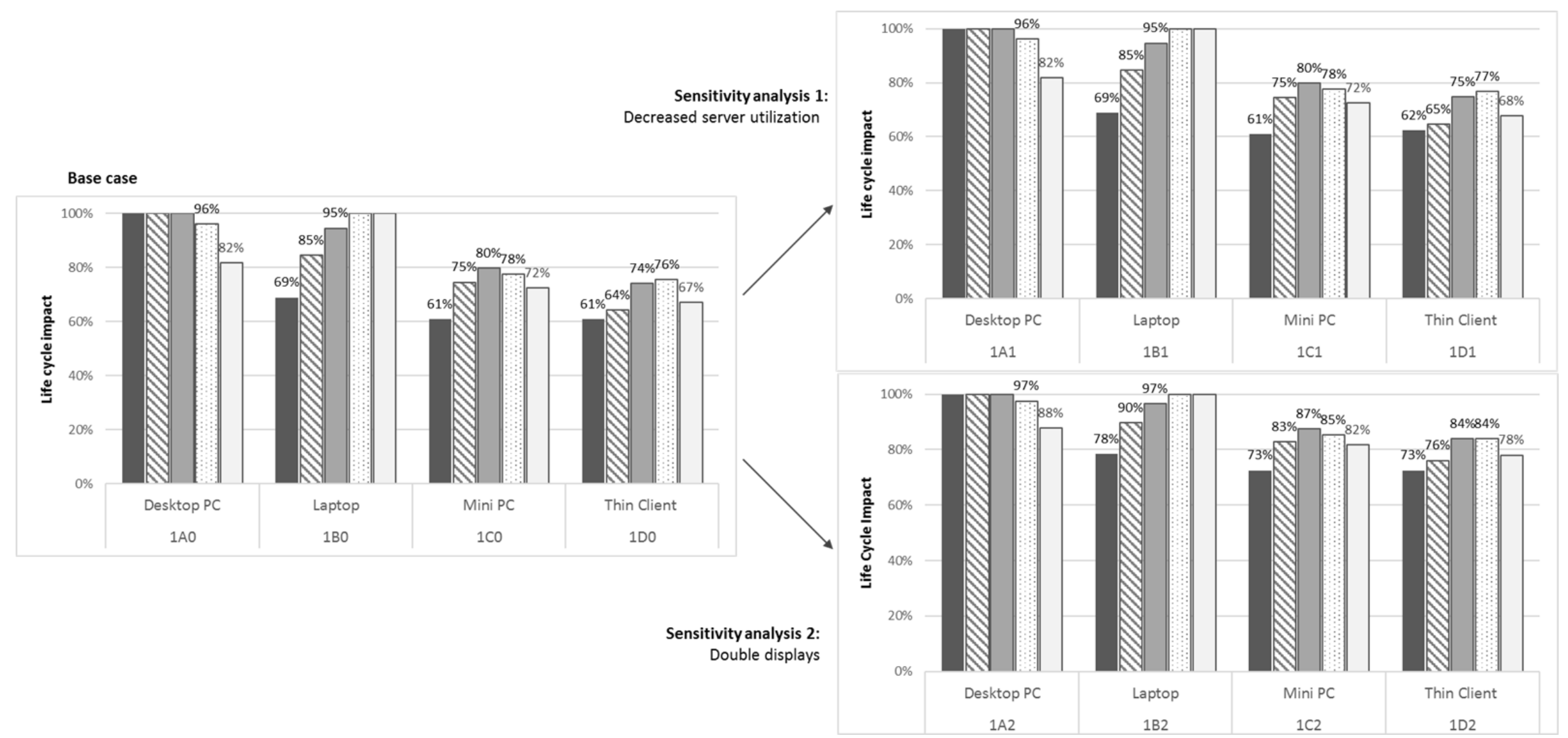

Figure SI 2: Relative life cycle impacts of the options Desktop PC, Laptop Mini PC and Thin Client in the base case and the two alternative modelling choices: (i) only 20 thin clients per server and (ii) two displays per electronic workstation. 


\section{Case study 2: Water provision}

Water dispensers substitute drinking water from glass or plastic bottles by preparing tap water. The preparation can include filtering, carbonation, cooling, heating, and, in some cases, energizing. The equipment used in Munich and currently under installation in Augsburg is called "water bars", the manufacturer is BRITA. Water dispensers in offices and public buildings reduces the amount of packaging waste. In agreement with interview results from Munich and the manufacturer, the supply of drinking water for an office with 25 employees is assessed (Barth-llg 2014, pers. comm.; BRITA lonox 2015, pers. comm.). In option $A$ and $B$, the water is supplied in common 0.7 liter refillable glass bottles with a respective transportation distance of 50 and $300 \mathrm{~km}$. Option $C$ features the use of 1.5 liter one-way PET bottles. In all three options, the transportation is within the system boundaries. The water dispenser "Sodamaster 50 Aquatower", which provides still and sparkling water directly out of the water pipe, is assessed along with the necessary carbon cylinders and filter systems. Respective to German consumption patterns, we assume a proportion of $60 \%$ sparkling and $40 \%$ still water (VDM 2016).

We assume a consumption of one liter per person per workday with 220 workdays a year. The LCA covers a period of 7 years which mirrors the realistic lifetime of the equipment (BRITA lonox 2015). The total amount of water is 38,500 liters.

The first part of the following table presents the data sources (Literature, Personal communication, and LCl data) used for modelling. The second part describes the modelling characteristics of each option in detail. The numbers in brackets refer to the data sources in the first part. 


\begin{tabular}{|c|c|c|}
\hline Case Study 2 & Reference \# & \\
\hline \multirow[t]{4}{*}{ Literature used for modelling } & 1 & (Fantin et al. 2014) \\
\hline & 2 & (Kauertz et al. 2010) \\
\hline & 3 & (Nessi et al. 2012) \\
\hline & 4 & (VDM 2016) \\
\hline \multirow{5}{*}{$\begin{array}{l}\text { Personal communication used for } \\
\text { modelling }\end{array}$} & 5 & (Barth-Ilg 2014, pers. comm.) \\
\hline & 6 & (BRITA lonox 2014, pers. comm.) \\
\hline & 7 & (BRITA lonox 2015, pers. comm.) \\
\hline & 8 & (Langer 2014, pers. comm.) \\
\hline & 9 & (Sodastream 2015, pers. comm.) \\
\hline \multirow{2}{*}{$\begin{array}{l}\mathrm{LCl} \text { data used for modelling (main } \\
\text { processes) }\end{array}$} & 10 & Aluminium, primary, ingot $\{\mathrm{GLO}\} \mid$ production | Alloc Def, $U$ \\
\hline & 11 & Brass $\{\mathrm{CH}\} \mid$ production | Alloc Def, $\mathrm{U}$ \\
\hline \multirow[t]{16}{*}{ ecoinvent v3.01 } & 12 & Carbon dioxide, liquid $\{R E R\} \mid$ production | Alloc Def, $U$ \\
\hline & 13 & Charcoal $\{$ GLO\}| production | Alloc Def, U \\
\hline & 14 & Copper $\{$ RER $\} \mid$ production, primary | Alloc Def, $U$ \\
\hline & 15 & EUR-flat pallet $\{$ RER $\} \mid$ production | Alloc Def, $U$ \\
\hline & 16 & Fleece, polyethylene $\{R E R\} \mid$ production | Alloc Def, $U$ \\
\hline & 17 & HDPE resin E \\
\hline & 18 & Iron-nickel-chromium alloy $\{$ RER\}| production | Alloc Def, $U$ \\
\hline & 19 & Metal working, average for aluminium product manufacturing $\{R E R\} \mid$ processing $\mid$ Alloc Def, $U$ \\
\hline & 20 & Packaging film, low density polyethylene $\{$ RER $\} \mid$ production | Alloc Def, $U$ \\
\hline & 21 & Polyethylene terephthalate, granulate, bottle grade $\{R E R\} \mid$ production | Alloc Def, $U$ \\
\hline & 22 & Polyethylene, low density, granulate $\{R E R\} \mid$ production | Alloc Def, $U$ \\
\hline & 23 & Polypropylene, granulate $\{R E R\} \mid$ production | Alloc Def, $U$ \\
\hline & 24 & Pump, 40W \{RoW\}| production | Alloc Def, $U$ \\
\hline & 25 & Steel, low-alloyed $\{R E R\} \mid$ steel production, converter, low-alloyed | Alloc Def, U \\
\hline & 26 & Synthetic rubber $\{R E R\} \mid$ production | Alloc Def, $U$ \\
\hline & 27 & Transport, freight, lorry $>32$ metric ton, EURO5 $\{R E R\} \mid$ transport, freight, lorry $>32$ metric ton, $E$ \\
\hline
\end{tabular}


SCOPE

\begin{tabular}{|c|c|c|c|c|}
\hline Usage time, years & $7[6]$ & & & \\
\hline Workdays per year & 220 & & & \\
\hline Employees & 25 & & & \\
\hline Consumption per person & 1 litre & & & \\
\hline Consumption, overall & 38,500 litres & & & \\
\hline Share of carbonated water & $60 \%[4]$ & & & \\
\hline \multicolumn{5}{|l|}{ MODELING } \\
\hline & Glass bottles, 50 km & Glass bottles, $300 \mathrm{~km}$ & One-way plastic bottles & Water dispenser \\
\hline \multicolumn{5}{|l|}{ Quantity } \\
\hline Volume, litres & 0.7 & 0.7 & 1.5 & 38,500 \\
\hline Usage times & $40[2]$ & $40[2]$ & 1 & \\
\hline Number of vessels & 1,375 & 1,375 & 25,667 & 1 \\
\hline Weight of vessel, kg & $0.5932[2]$ & $0.5932[2]$ & $0.033[2]$ & $51.1[7]$ \\
\hline Carbon cylinders, produced number & & & & $0.233[6]$ \\
\hline Carbon cylinders, weight, kg & & & & $1.400[7]$ \\
\hline Carbon cylinders packaging, weight, kg & & & & 0.6 \\
\hline Carbon cylinders, packaging, number & & & & 39 \\
\hline Filter, number & & & & $4[6]$ \\
\hline Filter, weight, kg & & & & $0.696[7]$ \\
\hline
\end{tabular}




\section{Packaging}

\begin{tabular}{|c|c|c|c|c|}
\hline Crates, $1.4 \mathrm{~kg}$, number & $4,584[2]$ & $4,584[2]$ & & \\
\hline EURO palets, $24 \mathrm{~kg}$, number & $102[2]$ & $102[2]$ & & 0.036 \\
\hline GDB palets, $30 \mathrm{~kg}$ number & $20[2]$ & $20[2]$ & & \\
\hline DHP palets, 9,5 kg, number & & & $107[2]$ & \\
\hline Plastic foil, $16 \mathrm{~g}$, number & & & $4,278[2]$ & \\
\hline Interim pad, $179 \mathrm{~g}$, number & & & $428[2]$ & \\
\hline Strech foil, 179g, number & & & $107[2]$ & \\
\hline Electricity, kWh & & & & $4,861.11[7]$ \\
\hline \multicolumn{5}{|l|}{ Transport } \\
\hline Road, distance, km & 50 & 300 & 300 & \\
\hline Road, tkm & $6,145.97$ & $36,876.00$ & $12,228.52$ & 132.75 \\
\hline
\end{tabular}




\section{Sensitivity Analysis 2: Water provision}

We assume two altered modelling choices for the case study of water provision.

In the first sensitivity case, we reduce the amount of employees from 25 to 10 . This reduces the amount of water from 37,500 liters to 15,000 liters.

In the second sensitivity case, we assume that only $20 \%$ of the water used is carbonated water, instead of $60 \%$. This effectively reduces the amount of carbon dioxide used and the amount of carbon cylinders required in the option $D$ (water dispenser).

\begin{tabular}{|c|c|c|c|}
\hline Modeling parameter & Base case $(2 \mathrm{AO}, 2 \mathrm{~B} 0,2 \mathrm{CO}, 2 \mathrm{D} 0)$ & Sensitivity case 1 (2A1, 2B1, 2C1, 2D1) & Sensitivity case $2(2 \mathrm{~A} 2,2 \mathrm{~B} 2,2 \mathrm{C} 2,2 \mathrm{D} 2)$ \\
\hline Employees, number & 25 (all options) & 10 (all options) & 25 (unchanged) \\
\hline Consumption, overall & 38,500 liters (all options) & 15,400 liters (all options) & 38,500 (unchanged) \\
\hline Share of carbonated water & $60 \%$ (all options) & $60 \%$ (unchanged) & $20 \%$ (all options) \\
\hline Carbon cylinders used, number & 39 (all options) & 39 (all options) & 13 (all options) \\
\hline
\end{tabular}

\section{Results sensitivity analyses water provision:}

\begin{tabular}{|c|c|c|c|c|c|c|c|c|c|c|c|c|c|}
\hline \multirow{2}{*}{$\begin{array}{l}\text { Sensitivity case } \\
\text { Modelling choice }\end{array}$} & & $2 \mathrm{AO}$ & $2 \mathrm{BO}$ & $2 \mathrm{CO}$ & 2D0 & $2 \mathrm{~A} 1$ & 2B1 & $2 \mathrm{C} 1$ & 2D1 & $2 \mathrm{~A} 2$ & 2B2 & $2 \mathrm{C} 2$ & $2 \mathrm{D} 2$ \\
\hline & & 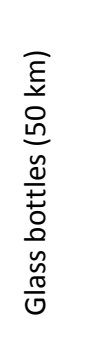 & 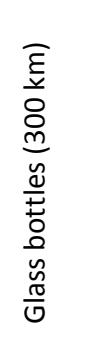 & 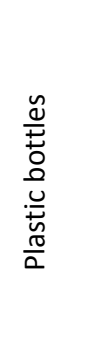 & 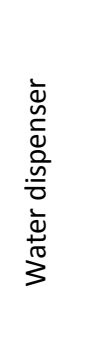 & $\begin{array}{l}\tilde{d} \\
\stackrel{d}{0} \\
\frac{0}{0} \\
\frac{0}{\varepsilon} \\
0 \\
0\end{array}$ & 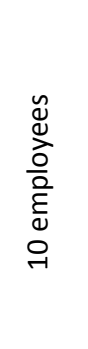 & 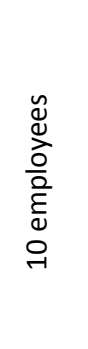 & 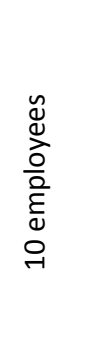 & 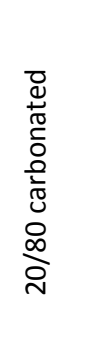 & 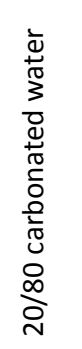 & 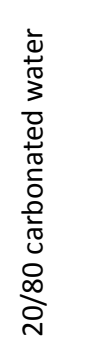 & 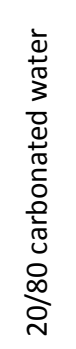 \\
\hline Waste Generation (Waste) & $\mathrm{kg}$ & 1321 & 1321 & 1172 & 79 & 529 & 529 & 469 & 63 & 1321 & 1321 & 1172 & 63 \\
\hline Global Warming Potential (GWP) & $\mathrm{kg} \mathrm{CO}_{2}$ eq & 1781 & 5207 & 6599 & 3336 & 712 & 2083 & 2640 & 3205 & 1667 & 5093 & 6485 & 3204 \\
\hline Water Depletion (WD) & $\mathrm{m}^{3}$ & 2614 & 4957 & 18860 & 3015 & 1045 & 1983 & 7544 & 2631 & 2311 & 4654 & 18557 & 2667 \\
\hline Metal Depletion (MD) & $\mathrm{kg} \mathrm{Fe} \mathrm{eq}$ & 110 & 327 & 349 & 417 & 44 & 131 & 140 & 405 & 99 & 317 & 339 & 405 \\
\hline Human Toxicity (Htox) & kg $1,4-\mathrm{DB}$ eq & 470 & 958 & 2205 & 1141 & 188 & 383 & 882 & 1080 & 415 & 903 & 2150 & 1079 \\
\hline
\end{tabular}




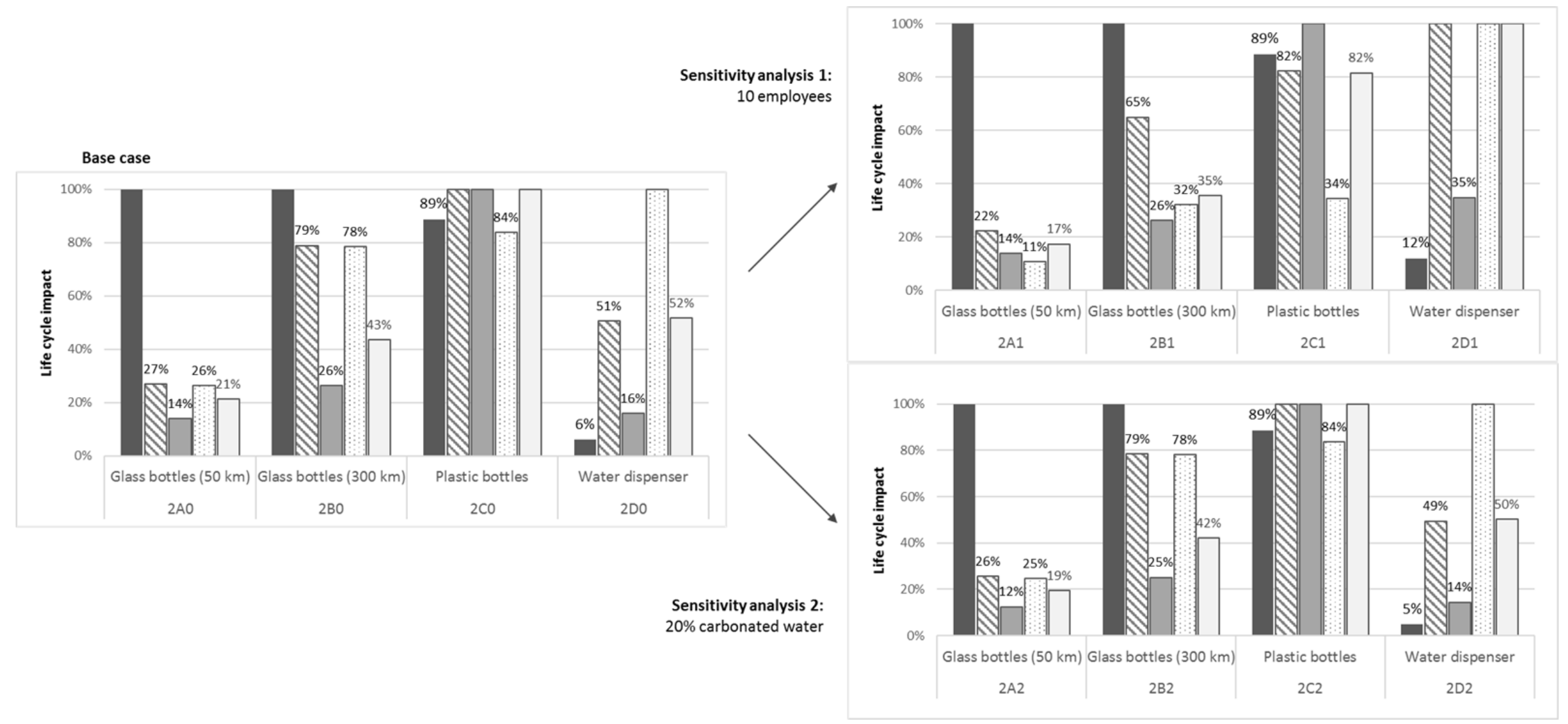

Figure SI 3: Relative life cycle impacts of the options glass bottles $(50 \mathrm{~km})$, glass bottles $(300 \mathrm{~km})$, plastic bottles and water dispenser in the base case and the two alternative modelling choices: (1) only 10 employees and (2) only $20 \%$ consumption share of carbonated water. 


\section{Case study 3: Refillables}

Public events and private events on public properties can be subject to legislative regulations concerning the type of dishes to use. These regulations have often been quoted as a means to prevent waste, if use of one-way dishes is prohibited (Hutner and Tuma 2016). Even if no prohibition is possible, the use of refillables can be encouraged. As the target group of this study are local authorities in Germany, the modelling is based on data for the soccer stadium of the Bundesliga club FC Augsburg. The average audience count is 29,163 people (Transfermarkt 2018), we assume that on average every person consumes one half liter beverage. We assessed the environmental performance of the containers necessary to serve all 17 home games of each season (Bundesliga 2016) for three seasons. Two kinds of one-way cups were compared to refillable cups. We modelled one-way polyethylene terephthalate (PET) cups with a weight of $11,5 \mathrm{~g}$ and polylactic acid (PLA) cups with $10 \mathrm{~g}$ (Pladerer et al.). The refillables are made of polypropylene (PP) with a weight of $56 \mathrm{~g}$ (Engelking-Mala 2015, pers. comm.). For the refillable cups, transport to and from the washing station as well as the washing process after every match is included in the scope. The average number of circulations for a cup in German sports stadiums is 107, which was set as the maximal possible value (Pladerer et al.). However, with events like the Bundesliga, the decrease of cups, for example if fans take the cup as a souvenir, has to be considered. An average use of 41 times for non-printed cups and 6 times for printed cups seems realistic (Deutsche Umwelthilfe 2014).

The first part of the following table presents the data sources (Literature, Personal communication, and LCl data) used for modelling. The second part describes the modelling characteristics of each option in detail. The numbers in brackets refer to the data sources in the first part. 


\section{Case Study 3}

\begin{tabular}{|c|c|c|}
\hline \multirow[t]{8}{*}{ Literature used for modelling } & 1 & (Bundesliga 2016) \\
\hline & 2 & (Deutsche Umwelthilfe 2014) \\
\hline & 4 & (Garrido and Alvarez del Castillo 2007) \\
\hline & 3 & (Kopytziok 2011) \\
\hline & 5 & (OVAM 2006) \\
\hline & 6 & (Pladerer et al.) \\
\hline & 7 & (Transfermarkt 2018) \\
\hline & 8 & (Vercalsteren et al. 2010) \\
\hline $\begin{array}{l}\text { Personal communication used for } \\
\text { modelling }\end{array}$ & 9 & (Engelking-Mala 2015, pers. comm.) \\
\hline \multirow{2}{*}{$\begin{array}{l}\mathrm{LCl} \text { data used for modelling (main } \\
\text { processes) }\end{array}$} & 10 & Polyethylene terephthalate (PET) granulate, production mix, at plant, bottle grade RER \\
\hline & 11 & Transport, freight, lorry $>32$ metric ton, EURO5 $\{$ RER $\} \mid$ transport, freight, lorry $>32$ metric ton, EURO5 | Alloc Def, U \\
\hline \multirow[t]{11}{*}{ ecoinvent v3.01 } & 12 & Electricity mix, AC, consumption mix, at consumer, $<1 \mathrm{kV}$ DE $\mathrm{S}$ \\
\hline & 13 & Corrugated board box $\{R E R\} \mid$ production | Alloc Def, $U$ \\
\hline & 14 & Packaging film, low density polyethylene $\{$ RER $\} \mid$ production | Alloc Def, $U$ \\
\hline & 15 & Polylactide, granulate $\{G L O\} \mid$ production | Alloc Def, $U$ \\
\hline & 16 & Transport, freight train $\{D E\} \mid$ processing $\mid$ Alloc Def, $U$ \\
\hline & 17 & Transport, freight, sea, transoceanic tanker $\{G L O\} \mid$ processing | Alloc Def, $U$ \\
\hline & 18 & Polypropylene, granulate $\{R E R\} \mid$ production | Alloc Def, $U$ \\
\hline & 19 & Tap water, at user \{Europe without Switzerland\}| tap water production and supply | Alloc Def, U \\
\hline & 20 & Sodium hydroxide $(50 \% \mathrm{NaOH})$, production mix/RER Mass \\
\hline & 21 & Printing ink, offset, without solvent, in $47.5 \%$ solution state $\{G L O\} \mid$ market for | Alloc Def, $U$ \\
\hline & 22 & Injection moulding $\{R E R\} \mid$ processing $\mid$ Alloc Def, $U$ \\
\hline
\end{tabular}


SCOPE

\begin{tabular}{|c|c|c|c|c|}
\hline Matches per season & $17[1]$ & & & \\
\hline Usage time, seasons & 3 & & & \\
\hline Visitors per match & $29,163[7]$ & & & \\
\hline \multicolumn{5}{|l|}{ MODELING } \\
\hline & PET & PLA & PP, printed & PP \\
\hline \multicolumn{5}{|l|}{ Quantity } \\
\hline Usage times & 1 & 1 & $6[2]$ & $41[6,2]$ \\
\hline Weight, g & $11.5[6]$ & $10[6]$ & $56[9]$ & $56[9]$ \\
\hline Number of cups, 1 season & 495,771 & 495,771 & 82,629 & 12,092 \\
\hline Number of cups, 3 seasons & $1,487,313$ & $1,487,313$ & 247,887 & 36,276 \\
\hline Waste generation, kg & $18,055.98$ & $15,890.88$ & $14,121.26$ & $2,066.72$ \\
\hline \multicolumn{5}{|l|}{ Production } \\
\hline Printing color, offset, $47,5 \%$ solvent & & & $0.0001596[5,3]$ & \\
\hline Electricity, kWh & $0.00605[5]$ & $0.00605[5]$ & $0.00605[5]$ & $0.00605[5]$ \\
\hline \multicolumn{5}{|l|}{ Packaging } \\
\hline PE-Film, g & $0.08[5]$ & $0.042857143[5]$ & $0.005[5]$ & $0.005[5]$ \\
\hline Cardboard box, $\mathrm{g}$ & $0.56[5]$ & $0.641428571[5]$ & $0.961538462[5]$ & $0.961538462[5]$ \\
\hline Electricity, kWh & $0.000045[5]$ & $0.000045[5]$ & $0.000045[5]$ & $0.000045[5]$ \\
\hline
\end{tabular}




\section{Transport to distributor}

\begin{tabular}{|c|c|c|c|c|}
\hline Road, distance, km & $100[5]$ & & $100[5]$ & $100[5]$ \\
\hline Road, tkm & 0.00115 & & 0.0056 & 0.0056 \\
\hline Sea, distance, km & & $6,000[5]$ & & \\
\hline Sea, tkm & & 0.06 & & \\
\hline Railway, distance, km & & $2,000[5]$ & & \\
\hline Railway, tkm & & 0.02 & & \\
\hline \multicolumn{5}{|l|}{ Transport, road } \\
\hline Distributor to stadium, $\mathrm{km}$ & $100[6]$ & $100[6]$ & $100[6]$ & $100[6]$ \\
\hline Stadium to washing, km & & & $100[6]$ & $100[6]$ \\
\hline \multicolumn{5}{|l|}{ Washing } \\
\hline Electricity, kWh & & & $0.0616[5]$ & $0.6006[5]$ \\
\hline Water, I & & & $0.704[5]$ & $6.864[5]$ \\
\hline detergent, $\mathrm{g}$ & & & $1.6[5]$ & $15.6[5]$ \\
\hline
\end{tabular}




\section{Sensitivity Analysis 3: Refillables}

We assume two altered modelling choices for the case study of refillables.

In the first sensitivity case, we reduce the usage times of the unprinted PP cups from 41 to 20.

In the second sensitivity case, we increase the usage times of the printed PP cups from 6 to 12 .

\begin{tabular}{|c|c|c|c|}
\hline Modeling parameter & Base case $(3 \mathrm{AO}, 3 \mathrm{BO}, 3 \mathrm{CO}, 3 \mathrm{DO})$ & Sensitivity case $1(3 \mathrm{C} 1)$ & Sensitivity case 2 (3D2) \\
\hline Usage times PP, printed (option C) & $6(3 \mathrm{Co})$ & $12(3 C 1)$ & 6 (unchanged) \\
\hline Usage times PP, unprinted (option D) & $41(3 D 0)$ & 41 (unchanged) & $20(3 \mathrm{D} 2)$ \\
\hline Washing processes per cup, PP, number & $5(3 C 0), 40(3 D 0)$ & $11(3 \mathrm{C} 1)$ & $10(3 \mathrm{D} 2)$ \\
\hline Number of cups, 3 seasons & $\begin{array}{l}1,487,313(3 \mathrm{AO} 0,3 \mathrm{BO}) \\
247,887(3 \mathrm{CO}) \\
36,276(3 \mathrm{DO})\end{array}$ & $123948(3 C 1)$ & 74366 (3D2) \\
\hline
\end{tabular}

\section{Results sensitivity analyses refillables:}

\begin{tabular}{|c|c|c|c|c|c|c|c|}
\hline Sensitivity case & & $3 \mathrm{AO}$ & 3B0 & $3 \mathrm{CO}$ & $3 \mathrm{C} 1$ & 3D0 & $3 \mathrm{D} 2$ \\
\hline Modelling choice & & PET & PLA & PP, printed & 12 times of useage & PP & 20 times of useage \\
\hline Waste Generation (Waste) & $\mathrm{kg}$ & 18056 & 15891 & 14121 & 7061 & 2067 & 4236 \\
\hline Global Warming Potential (GWP) & $\mathrm{kg} \mathrm{CO}_{2} \mathrm{eq}$ & 86748 & 75084 & 61470 & 40435 & 25556 & 32021 \\
\hline Water Depletion (WD) & $m^{3}$ & 104772 & 230818 & 83227 & 42751 & 14122 & 26561 \\
\hline Metal Depletion (MD) & kg Fe eq & 815 & 3178 & 698 & 419 & 222 & 308 \\
\hline Human Toxicity (Htox) & $\mathrm{kg} 1,4-\mathrm{DB}$ e & 9044 & 24330 & 7539 & 4116 & 1695 & 2747 \\
\hline
\end{tabular}




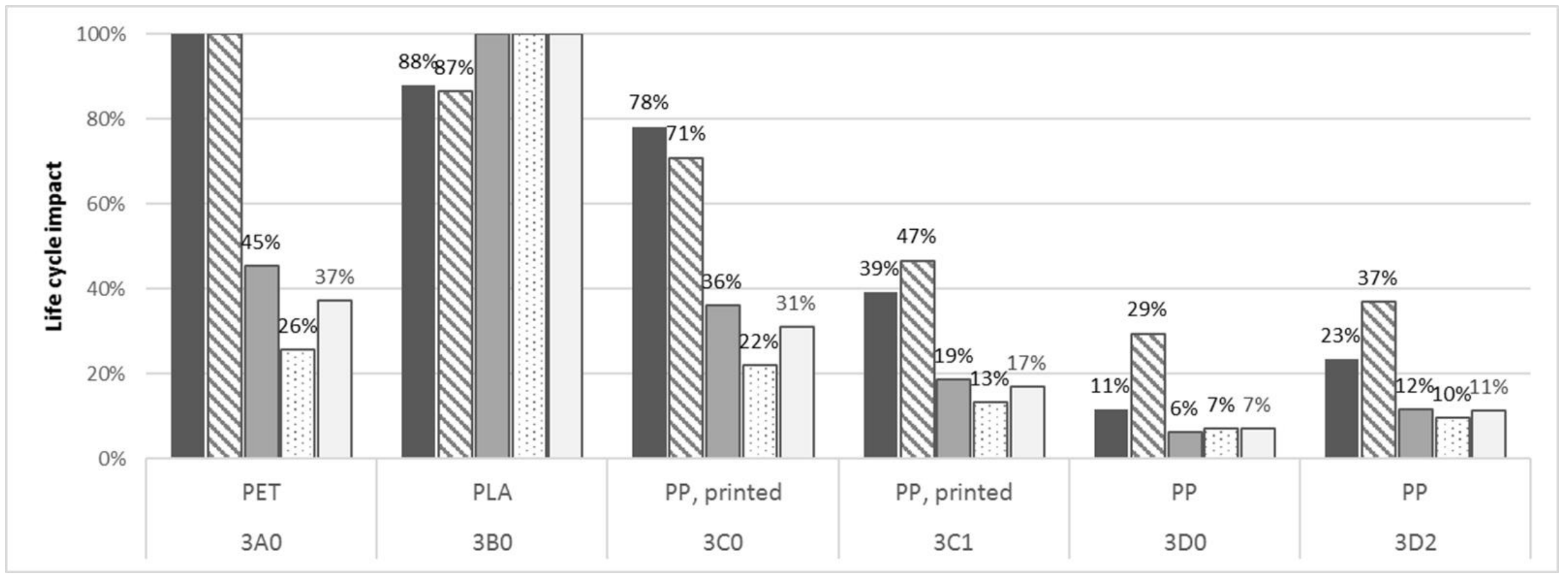

Figure SI 4: Relative life cycle impacts of the options PET cups, PLA cups, printed PP cups and unprinted PP cups and the two alternative modelling choices: (1) 12 usage times for printed PP cups and (2) only 20 usage times for unprinted PP cups. 


\section{Case study 4: E-Government}

The distribution of online forms instead of actual paper forms is supposed to not only reduce paper waste, but the environmental impacts related to paper production and necessary transport. However, recent studies show ambiguous results in the comparison of paper and online communication (Arushanyan et al. 2014). As indicated by (Achachlouei and Moberg 2015), the number of users can be decisive. Therefore, we model the distribution of forms for the application in a local authority administration.

Online forms are an element of the transition towards e-government. Up to now, the communication between citizens and public administration mostly consists of letters, fax messages, phone calls and personal conversations (Mehlich 2002). In Germany, the average amount of contacts between each citizen and responsible public administration office is 2 to 5 times a year (Initiative D21 and ipima 2014). For the modelling, we assume 4 contacts per year over a period of 5 years for each citizen. $50 \%$ of these contacts are assumed to require forms of some sort.

The exchange of these forms takes place in one of 5 ways: A paper form is provided by the public administration. This form is either filled in by the citizen at the public administration office (option A) or sent to the citizen by mail (option B). If filled in at the public administration office, we the transportation mode is modelled according to the modal split of Germany (UBA 2012). For option B, we model the environmental impacts of the mail shipment according to the Deutsche Post AG (2003). If the form is provided electronically, there are three major options we identified within the personal interviews. If a handwritten signature is needed, the form can be printed at home and then brought back to the public administration office personally (option C) or sent by mail (option D). If filling in the form and signing it can take place electronically as well, it can be delivered digitally. For this, we assume a processing time of 5 minutes per page and model the respective energy demand.

The first part of the following table presents the data sources (Literature, Personal communication, and LCl data) used for modelling. The second part describes the modelling characteristics of each option in detail. The numbers in brackets refer to the data sources in the first part. 


\section{Case Study 4}

\begin{tabular}{|c|c|c|}
\hline \multirow[t]{7}{*}{ Literature used for modelling } & 1 & (Deutsche Post AG 2003) \\
\hline & 2 & (Maga et al. 2013) \\
\hline & 3 & (Mehlich 2002) \\
\hline & 4 & (Mirabella et al. 2013) \\
\hline & 5 & (Initiative D21 and ipima 2014) \\
\hline & 6 & (Quack and Möller 2005) \\
\hline & 7 & (UBA 2012) \\
\hline \multirow{2}{*}{$\begin{array}{l}\text { Personal communication used for } \\
\text { modelling }\end{array}$} & 8 & (Geiger 2014, pers. comm.) \\
\hline & 9 & (Hüngerl 2013, pers. comm.) \\
\hline \multirow{2}{*}{$\begin{array}{l}\text { LCI data used for modelling (main } \\
\text { processes) }\end{array}$} & 10 & Operation, computer, desktop, with liquid crystal display, active mode \{Europe without Switzerland\}| processing | Alloc Def, U \\
\hline & 11 & Printed paper $\{D E\} \mid$ operation, printer, laser, black/white, per kg | Alloc Def, $U$ \\
\hline \multirow[t]{7}{*}{ ecoinvent v3.01 } & 12 & Printed paper, offset $\left\{\mathrm{CH}_{-} \mathrm{vg} \mid\right\} \mid$ offset printing, per kg printed paper | Alloc Def, U \\
\hline & 13 & Transport, freight, light commercial vehicle \{Europe without Switzerland\}| processing | Alloc Def, U \\
\hline & 14 & Transport, freight, lorry 3.5-7.5 metric ton, EURO4 \{RER\}| transport, freight, lorry 3.5-7.5 metric ton, EURO4 | Alloc Def, U \\
\hline & 15 & Transport, passenger car $\{$ RER $\} \mid$ processing | Alloc Def, U \\
\hline & 16 & Transport, passenger, bicycle| processing | Alloc Def, $U$ \\
\hline & 17 & Transport, regular bus $\{$ RoW $\} \mid$ processing | Alloc Def, $U$ \\
\hline & 18 & Transport, tram $\{D E\} \mid$ processing $\mid$ Alloc Def, $U$ \\
\hline
\end{tabular}




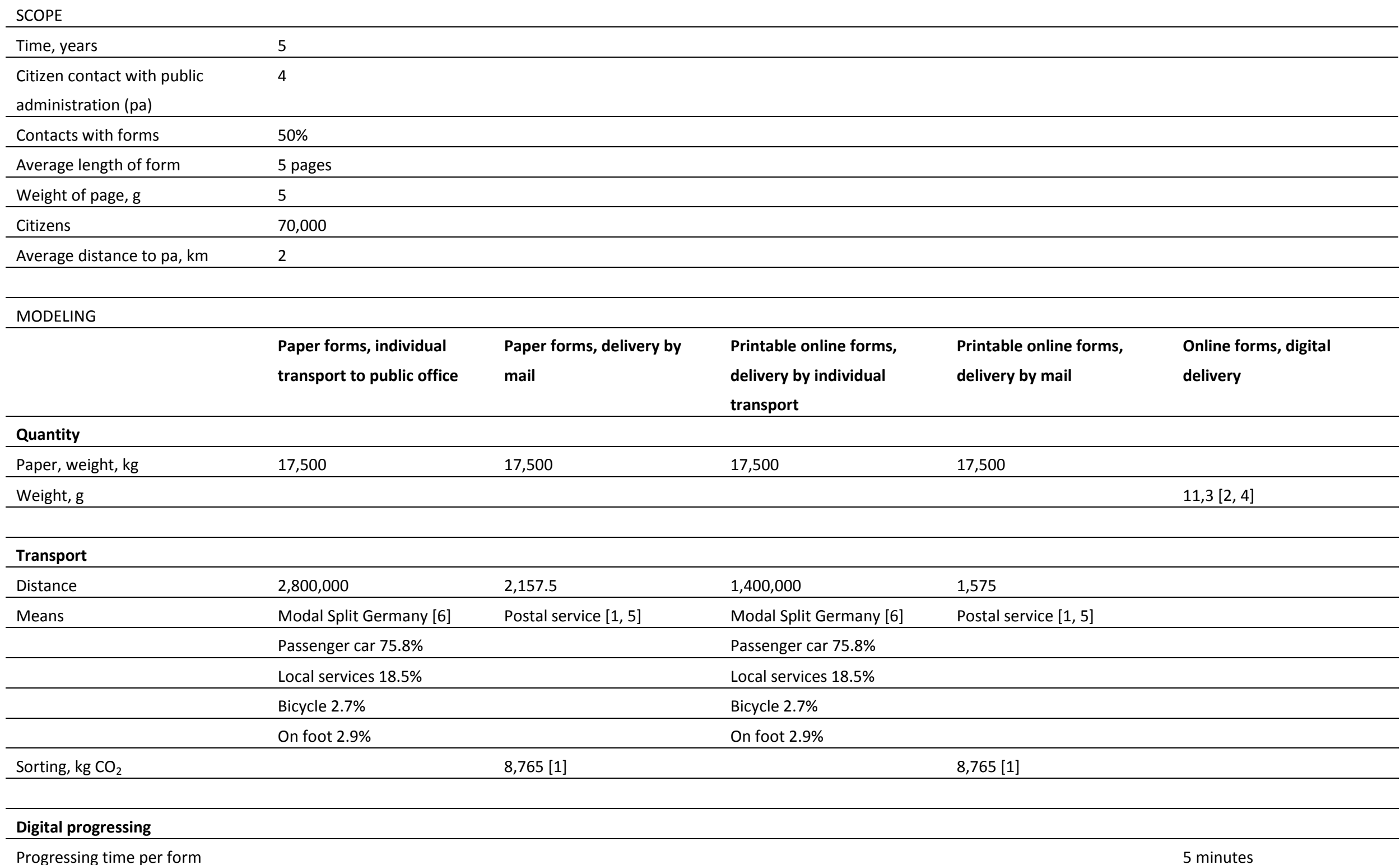




\section{Sensitivity Analysis 4: E-Government}

We assume two altered modelling choices for the case study of e-government.

In the first sensitivity case, we assume that all transportation to the administration is handled by local public transportation, instead of the German modal split. In the second sensitivity case, we increase the forms have double the average length, making it 10 pages instead of 5 pages.

\begin{tabular}{lll} 
Modeling parameter & Base case (4A0, 4B0, 4C0, 4D0, 4E0) & Sensitivity case 1 (4A1, 4C1) \\
\hline Transportation mix & German modal mix & Only public transportation \\
& $\begin{array}{l}(75,8 \% \text { passenger car, } 18.5 \% \text { local services, } \\
\text { (50\% tram, 50\% bus) }\end{array}$ & \\
\hline Average form length, pages & 5 (all options) & 5 (unchanged)
\end{tabular}

\section{Results sensitivity analyses E-government:}

Sensitivity case

$4 \mathrm{AO}$

Modelling choice

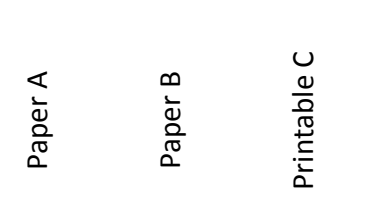

$4 \mathrm{D}$

$4 \mathrm{~A} 1 \quad 4 \mathrm{~B} 1$

$4 C 1 \quad 4 D 1$

$4 \mathrm{E} 1 \quad 4 \mathrm{~A}$

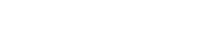

$(20)$

\section{Waste Generation}

kg

$17500 \quad 17500$

$\frac{0}{\frac{0}{0}}$

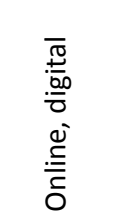

4B2 $4 \mathrm{C} 2 \quad 4 \mathrm{D} 2$

$4 \mathrm{E} 2$

\begin{tabular}{|c|c|c|c|c|c|c|c|c|c|c|c|c|c|c|c|c|}
\hline $\begin{array}{l}\text { Waste Generation } \\
\text { (Waste) }\end{array}$ & $\mathrm{kg}$ & 17500 & 17500 & 17500 & 17500 & 11 & 17500 & 17500 & 17500 & 17500 & 11 & 35000 & 35000 & 35000 & 35000 & 23 \\
\hline $\begin{array}{l}\text { Global Warming Potential } \\
\text { (GWP) }\end{array}$ & $\mathrm{kg} \mathrm{CO}_{2}$ eq & 793987 & 61904 & 413647 & 52924 & 35950 & 322223 & 61904 & 177765 & 52924 & 35950 & 844405 & 115043 & 455508 & 97082 & 70063 \\
\hline Water Depletion (WD) & $\mathrm{m}^{3}$ & 981083 & 206717 & 597187 & 211083 & 218176 & 624771 & 206717 & 419031 & 211083 & 218176 & 1184915 & 413433 & 805749 & 422166 & 435772 \\
\hline Metal Depletion (MD) & kg Fe eq & 83882 & 2460 & 45429 & 4820 & 6993 & 17659 & 2460 & 12318 & 4820 & 6993 & 86069 & 4920 & 50011 & 9640 & 13854 \\
\hline Human Toxicity (Htox) & kg 1,4-DB eq & 255673 & 22413 & 147089 & 30780 & 40385 & 114273 & 22413 & 76390 & 30780 & 40385 & 277251 & 44826 & 177133 & 61560 & 80434 \\
\hline
\end{tabular}


Sensitivity analysis 1: Modal split 100\% public transportation

Base case

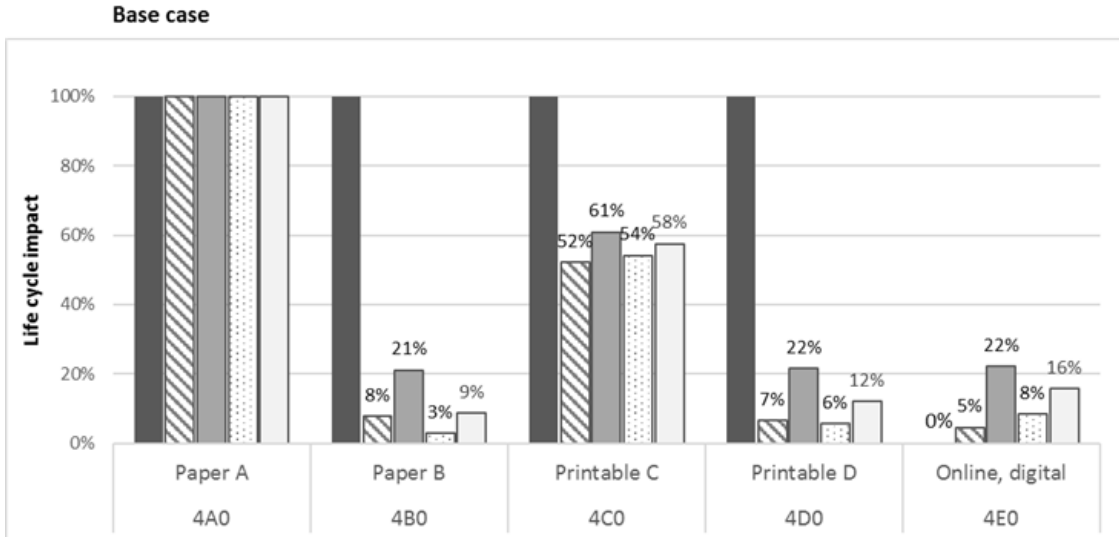

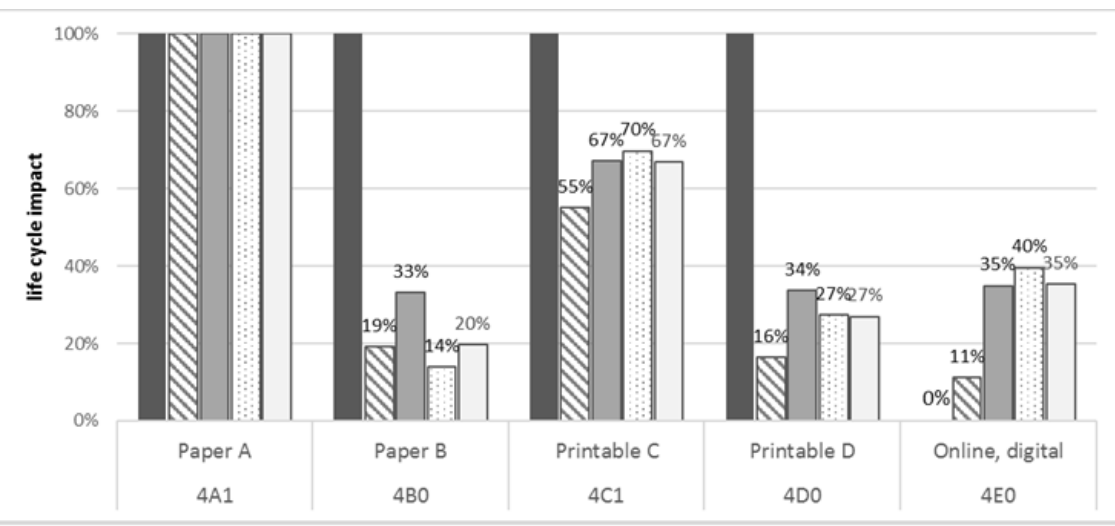

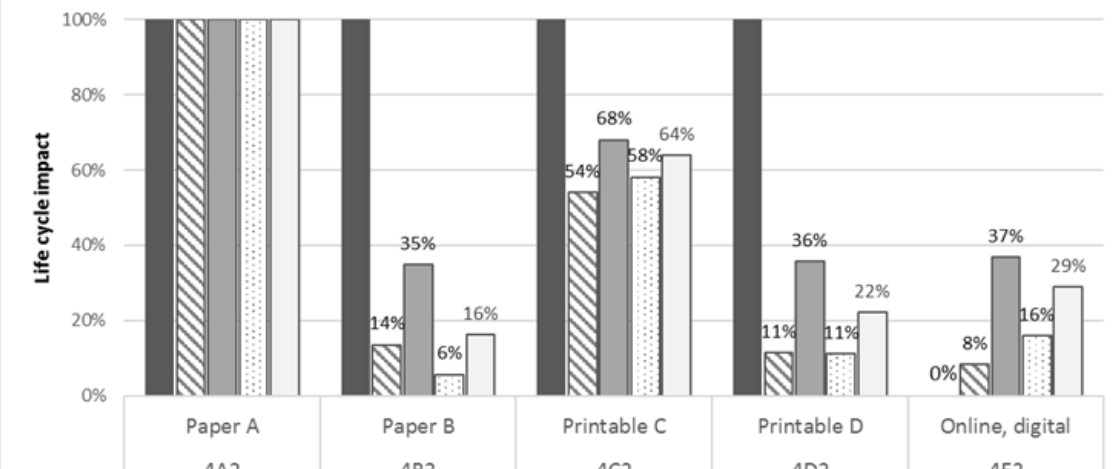

$4 \mathrm{C2}$

4D2

$4 E 2$

Sensitivity analysis 2 Double form length

$4 B 2$

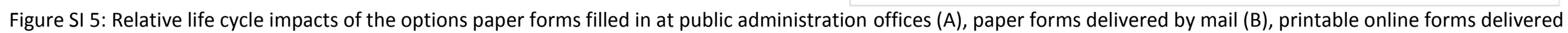
by individual transport (C), printable online forms delivered by mail (D) and online forms with digital delivery as well as the two alternative modelling choices: (1) transportation by local service public transportation and (2) doubled form length. 


\section{Case study 5: Lighting}

Replacing common lights for communal fairs with a long-life and energy-efficient substitute is thought to reduce the waste generation and environmental impact of this particular material stream enormously. In Augsburg this conviction lead to a replacement of the lighting for the Christmas fair with light emitting diodes (LED).

The scope for this LCA is the necessary light stream for lighting a communal fair. We assess the environmental impacts of incandescent light bulbs (ILB), compact fluorescent lamps (CFL) and LED for 10 years. The case study this LCA is based on is Augsburg (Hüngerl 2013, pers. comm.). The fair is open for 31 days with 8 hours of lighting every day. Roughly 3,500 lamps are used for illuminating the main market place and pedestrian zone. We assume 415 lumen per lamp. For modelling reasons, we base the functional unit on the overall light stream for this setting, which amounts to 3,602,200,000 lumen hours. The number of lamps necessary to provide this light stream varies between the technologies, as the lamps have different life spans and, thus, a different amount of lumen hours per lamp.

The first part of the following table presents the data sources (Literature, Personal communication, and LCI data) used for modelling. The second part describes the modelling characteristics of each option in detail. The numbers in brackets refer to the data sources in the first part. 


\section{Case Study 5}

\begin{tabular}{|c|c|c|}
\hline \multirow[t]{6}{*}{ Literature used for modelling } & 1 & (DEL-KO) \\
\hline & 2 & (LEDVANCE 2018a) \\
\hline & 3 & (LEDVANCE 2018b) \\
\hline & 4 & (OSRAM 2016) \\
\hline & 6 & (OSRAM 2008) \\
\hline & 7 & (OSRAM 2011) \\
\hline \multirow{2}{*}{$\begin{array}{l}\text { LCl data used for modelling (main } \\
\text { processes) }\end{array}$} & 9 & Aluminium, primary, ingot $\{G L O\} \mid$ production | Alloc Def, $U$ \\
\hline & 10 & Argon, liquid $\{R E R\} \mid$ production | Alloc Def, $U$ \\
\hline \multirow[t]{10}{*}{ ecoinvent v3.01 } & 11 & Brass $\{\mathrm{CH}\} \mid$ production | Alloc Def, $\mathrm{U}$ \\
\hline & 12 & Calcium carbonate $>63$ microns, production, at plant EU-27 S \\
\hline & 13 & Copper $\{\mathrm{RER}\} \mid$ production, primary | Alloc Def, $U$ \\
\hline & 18 & Mercury $\{G L O\} \mid$ production | Alloc Def, U \\
\hline & 19 & Molybdenum $\{R E R\} \mid$ production | Alloc Def, $U$ \\
\hline & 20 & Nickel sulfate $\{G L O\} \mid$ production | Alloc Def, $U$ \\
\hline & 21 & Phosphorous chloride $\{R E R\} \mid$ production | Alloc Def, $U$ \\
\hline & 22 & Polycarbonate $\{$ RER $\} \mid$ production | Alloc Def, $U$ \\
\hline & 23 & Printed wiring board, surface mounted, unspecified, $\mathrm{Pb}$ free $\{\mathrm{GLO}\} \mid$ market for | Alloc Def, $U$ \\
\hline & 24 & Screw_Steel, low-alloyed $\{R E R\} \mid$ steel production, electric, low-alloyed | Alloc Def, U \\
\hline
\end{tabular}




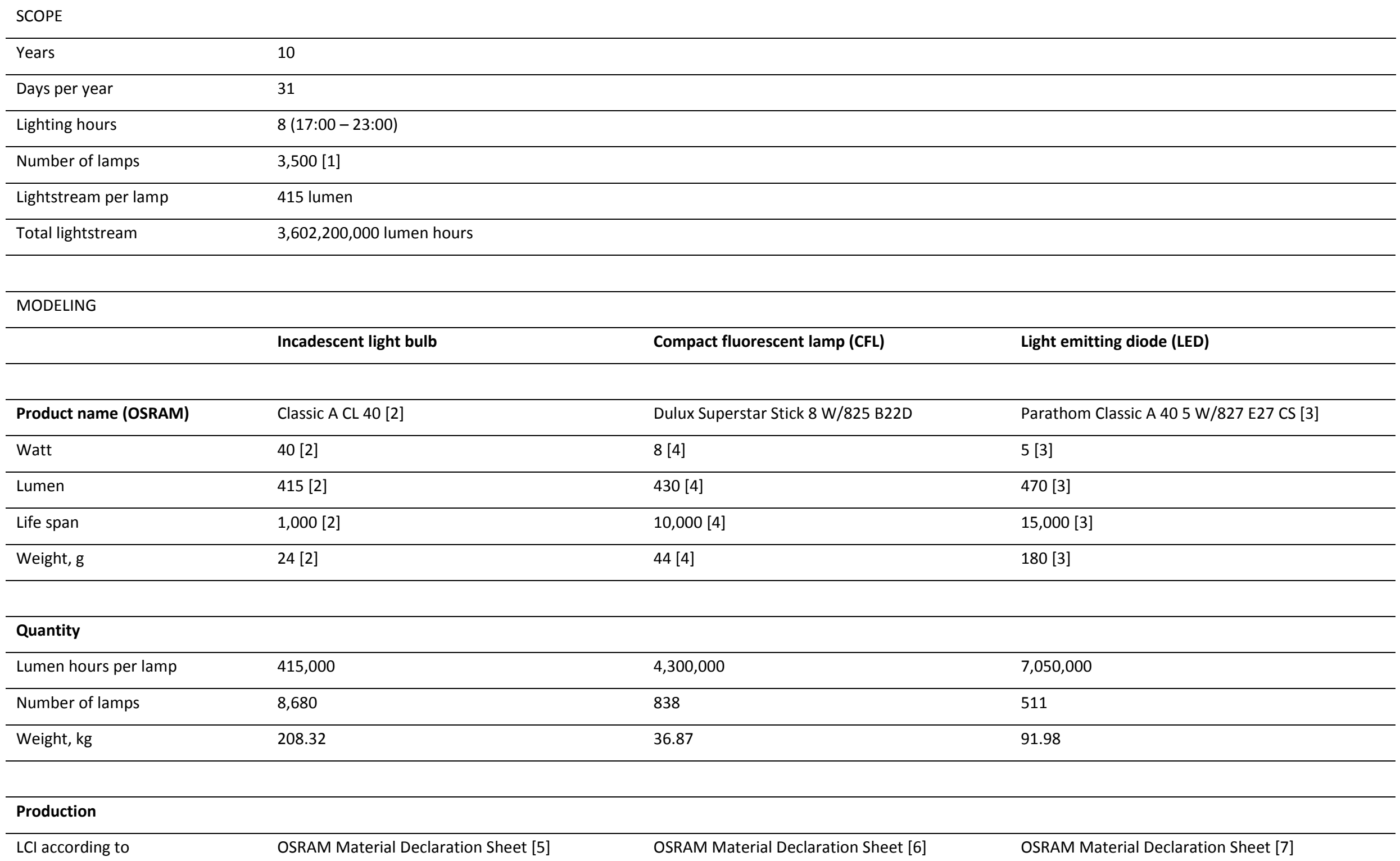


Packaging

Cardboard box, $\mathrm{g}$

84

$73.31[4]$

$74.2[3]$

Electricity, kWh

861,056

$16,625.92$

$6,336.4$ 


\section{Sensitivity Analysis 5: Lighting}

We assume only one altered modelling choice for the case study of lighting.

In this sensitivity case, we assume that despite the potential longer technical lifetime of CFLs and LEDs, all light bulbs are not used anymore after the 10 year period of the functional unit. This could be the case e.g. due to a changed lighting concept for the Christmas fair, or due to technological improvements which justify the installation of even more energy efficient lighting systems.

Modeling parameter

Base case (5AO, 5BO, 5CO)

Sensitivity case 1 (5A1, 5B1, 5C1)

\begin{tabular}{|c|c|c|}
\hline ILBs total over 10 years, number & $8,680(5 A 0)$ & $8,680(5 A 1)$ \\
\hline CFLs total over 10 years, number & 838 (5B0) & $3,378(5 B 1)$ \\
\hline LEDs total over 10 years, number & $511(5 \mathrm{CO})$ & $30,90(5 C 1)$ \\
\hline
\end{tabular}

\section{Results sensitivity analysis lighting:}

\begin{tabular}{|c|c|c|c|c|c|c|c|}
\hline Sensitivity case & & $5 \mathrm{AO}$ & $5 \mathrm{BO}$ & $5 \mathrm{CO}$ & $5 \mathrm{~A} 1$ & $5 B 1$ & $5 \mathrm{C} 1$ \\
\hline Modelling choice & & ILB & CFL & LED & Basecase & 3378 lamps (430 Lumen) & 3090 lamps (470 Lumen) \\
\hline Waste Generation (Waste) & $\mathrm{kg}$ & 937 & 98 & 135 & 937 & 149 & 556 \\
\hline Global Warming Potential (GWP) & $\mathrm{kg} \mathrm{CO} \mathrm{C}_{2}$ eq & 611800 & 15860 & 10072 & 611800 & 23733 & 33691 \\
\hline Water Depletion (WD) & $\mathrm{m}^{3}$ & 5659 & 10005 & 21401 & 5659 & 40236 & 129350 \\
\hline Metal Depletion (MD) & kg Fe eq & 2210 & 2820 & 4125 & 2210 & 11356 & 24935 \\
\hline Human Toxicity (Htox) & kg 1,4-DB eq & 12515 & 15480 & 22144 & 12515 & 61620 & 133375 \\
\hline
\end{tabular}


Base case

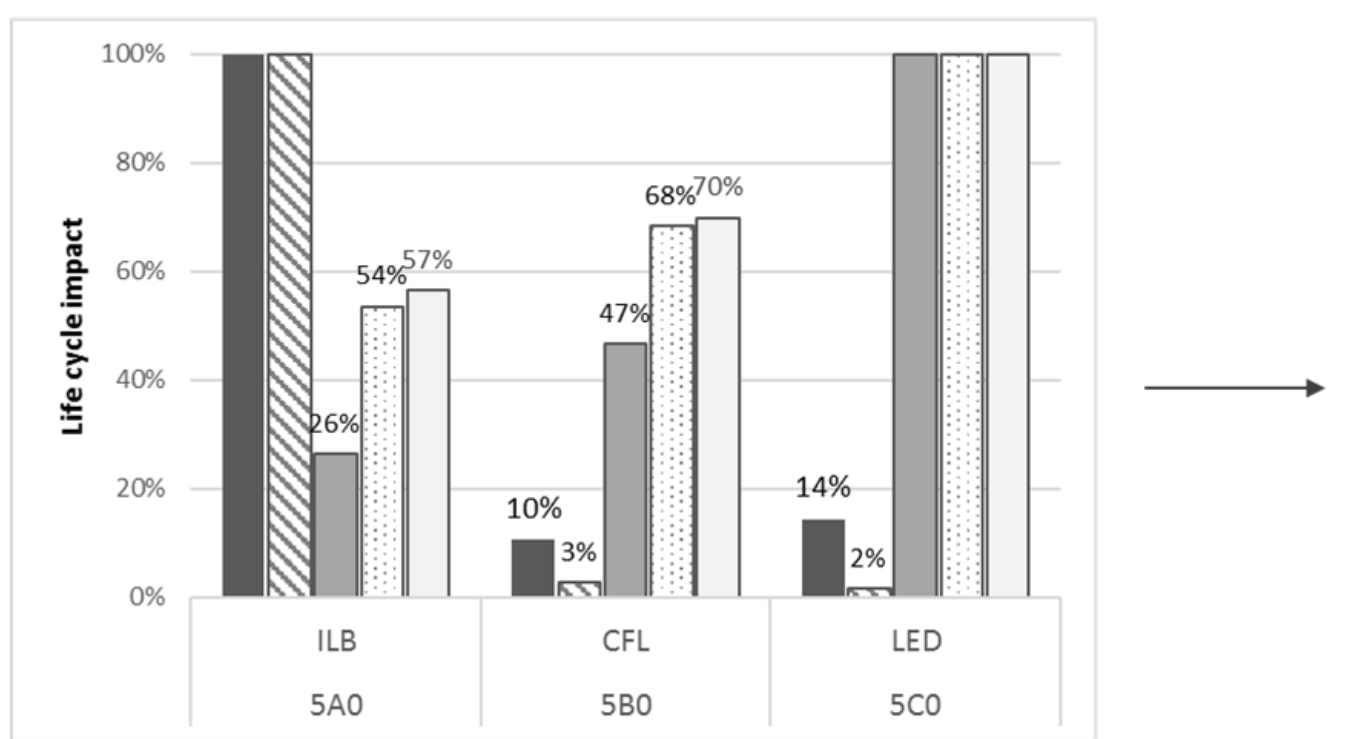

Sensitivity analysis:

Light bulbs turned into waste after 10 years

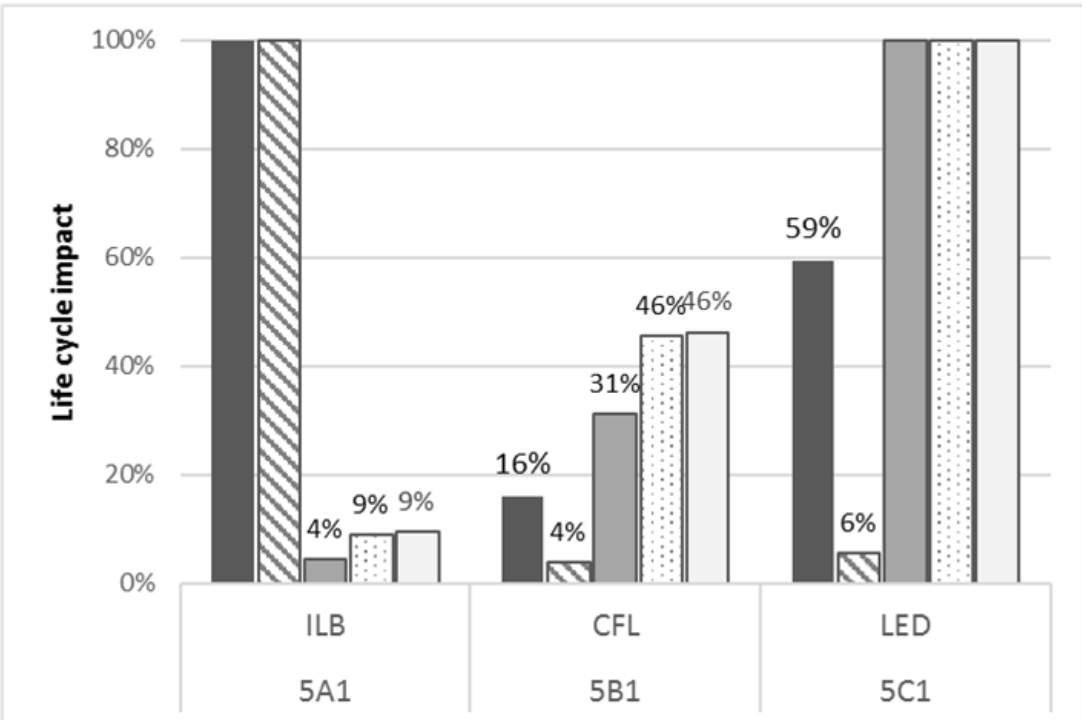

Figure SI 6: Relative life cycle impacts of the options incandescent light bulbs (ILB), compact fluorescent lambs (CFL) and light-emitting diodes (LED) as well as for the alternative modelling scenario with waste generation after 10 years regardless of technical lifetime. 


\section{SI References}

Achachlouei, M.A. and Å. Moberg. 2015. Life Cycle Assessment of a Magazine, Part II: A Comparison of Print and Tablet Editions. Journal of Industrial Ecology 19(4): 590-606. http://doi.wiley.com/10.1111/jiec.12229.

Arushanyan, Y., E. Ekener-Petersen, and G. Finnveden. 2014. Lessons learned - Review of LCAs for ICT products and services. Computers in Industry 65(2): 211-234. http://linkinghub.elsevier. com/retrieve/pii/S0166361513002133.

Barth-Ilg, S. 2014. Personal communication with S. Barth-Ilg. Munich, April 2.

BRITA lonox. 2014. Personal communication with BRITA Ionox. March 9.

BRITA lonox. 2015. Personal communication with BRITA Ionox. June 9.

Bundesliga. 2016. Spieltagsübersicht. https://www.bundesliga.com/de/bundesliga/spieltag/. Accessed August 25, 2016.

DEL-KO. Sparsame LED Weihnachtsbeleuchtung auf Augsburger Christkindlesmarkt. 2016. https://www.del-ko.de/augsburg-led-weihnachtsbeleuchtung. Accessed August 30, 2016.

Deutsche Post AG. 2003. Natürlich vernetzt: Deutsche Post World Net: Umweltbericht 2003. https://dpdhl.com/content/dam/dpdhl/de/media-

center/responsibility/dpwn_umweltbericht2003_de.pdf. Accessed July 16, 2018.

Deutsche Umwelthilfe. 2014. 1:0 für Mehrweg: Vergleich der Umweltauswirkungen von Mehrwegbechern und biologisch abbaubaren PLA-Einwegbechern in deutschen Fußballstadien. https://duh.de/fileadmin/user_upload/download/Projektinformation/Mehrwegschutz/170816 _Bechersysteme-Fussballbundesligen_Hintergrundpapier_2017.pdf. Accessed July 16, 2018.

Duan, H., M. Eugster, R. Hischier, M. Streicher-Porte, and J. Li. 2009. Life cycle assessment study of a Chinese desktop personal computer. Science of The Total Environment 407(5): 1755-1764. http://linkinghub.elsevier.com/retrieve/pii/S0048969708011170.

Engelking-Mala, T. 2015. Personal communication with T. Engelking-Mala. November 9.

Fantin, V., S. Scalbi, G. Ottaviano, and P. Masoni. 2014. A method for improving reliability and relevance of LCA reviews: The case of life-cycle greenhouse gas emissions of tap and bottled water. Science of The Total Environment 476-477: 228-241. http://linkinghub.elsevier.com/ retrieve/pii/S0048969713016057.

Fraunhofer UMSICHT. 2011. Studie Thin Clients 2011 - Ökologische und ökonomische Aspekte virtueller Desktops. https://www.igel.com/uploads/media/thinclients2011-de-2.pdf. Accessed July 9, 2018.

Fujitsu. 2014. Fujitsu ESPRIMO Q510 Desktop PC: Datenblatt. http://wiedervermarktung.de/ shop/images/datenblatt/db_esprimo_q510_de.pdf. Accessed July 16, 2018.

Garrido, N. and M.D. Alvarez del Castillo. 2007. Environmental evaluation of single-use and reusable cups. The International Journal of Life Cycle Assessment 12(4): 252-256. http://www. springerlink.com/index/10.1065/lca2007.05.334.

Geiger, R. 2014. Personal communication with R. Geiger. Miesbach, January 21.

Hüngerl, S. 2013. Personal communication with S. Hüngerl. Augsburg, November 13.

Hutner, P. and A. Tuma. 2016. Leitfaden zur Erstellung kommunaler Abfallvermeidungskonzepte. https://stmuv.bayern.de/themen/abfallwirtschaft/haushalts_gewerbeabfaelle/abfallvermeidun g/leitfaden_kommunale_abfallvermeidung.htm. Accessed July 9, 2018.

Initiative D21 and ipima. 2014. eGovernment Monitor 2014: Nutzung und Akzeptanz von elektronischen Bürgerdiensten im internationalen Vergleich. http://www.egovernment- 
monitor.de/fileadmin/uploads/Studien/2014/eGovMon2014_web.pdf. Accessed July 16, 2018.

IVF. 2007. Preparatory studies for Eco-design Requirements of EuPs: Lot 3 Personal Computers (desktops and laptops) and Computer Monitors: Final Report (Task 1-8). https://www.eupnetwork.de/fileadmin/user_upload/Produktgruppen/Lots/Final_Documents/EuP_Lot3_PC_Fina IReport.pdf. Accessed July 16, 2018.

Kauertz, B., A. Döhner, and A. Detzel. 2010. PET Ökobilanz 2010: Ökobilanzielle Untersuchung verschiedener Verpackungssysteme für kohlensäurehaltige Mineralwässer und Erfrischungsgetränke sowie stille Mineralwässer. http://docplayer.org/45069236-Petoekobilanz-endbericht-ifeu-institut-fuer-energieund-umweltforschung-heidelberg-gmbh.html. Accessed July 9, 2018.

Koppmair, W. and C. Wenger. 2013. Personal communication with P. Koppmair and C. Wenger. December 4.

Kopytziok, N. 2011. Paradebeispiele: Bei Straßenfesten können Kommunen und Veranstalter auf vorbildliche Weise Abfälle vermeiden. ReSource 1(37-42).

Langer, G. 2014. Personal communication with G. Langer. July 29.

LEDVANCE. 2018a. Life cycle analysis of an LEDVANCE incandescent lamp. https://www.ledvance. com/company/sustainability/environmental/product-lifecycle-management/lca-of-anincandescent-lamp/index.jsp. Accessed April 24, 2018.

LEDVANCE. 2018b. Parathom Classic A. https://www.ledvance.de/produkte/lampen/ledlampen/professional-led-lampen-mit-klassischen-kolbenformen/parathom-classic-a/index.jsp. Accessed April 12, 2018.

Maga, D., M. Hiebel, and C. Knermann. 2013. Comparison of two ICT solutions: desktop PC versus thin client computing. The International Journal of Life Cycle Assessment 18(4): 861-871. http://link.springer.com/10.1007/s11367-012-0499-3.

Mairgünther, C. and K. Lopes. 2014. Personal communication with C. Mairgünther and K. Lopes. München, July 9.

Mayer, H.-J. 2013. Personal communication with H.-J. Mayer. Augsburg, December 18.

Mehlich, H. 2002. Electronic Government. Wiesbaden: Gabler Verlag. http://link.springer. com/10.1007/978-3-322-87000-1.

Mirabella, N., L. Rigamonti, and S. Scalbi. 2013. Life cycle assessment of Information and Communication Technology application: a case study of dematerialization in the Italian Public Administration. Journal of Cleaner Production 44: 115-122. http://linkinghub.elsevier.com/ retrieve/pii/S0959652612006348.

Nessi, S., L. Rigamonti, and M. Grosso. 2012. LCA of waste prevention activities: A case study for drinking water in Italy. Journal of Environmental Management 108: 73-83. http://linkinghub.elsevier.com/retrieve/pii/S0301479712002149.

OSRAM. 2007. Classic A CL 4OW E27. Material Declaration Sheet and RoHS Compliance Declaration. https://www.osram.com/media/resource/HIRES/333050/181415/osram-material-declarationsheet_gls.pdf. Accessed July 16, 2018.

OSRAM. 2008. DEL Superstar 8W. Material Declaration Sheet and RoHS Compliance Declaration. http://www.osram.com/media/resource/HIRES/333047/79486/osram-material-declarationsheet_cfl.pdf. Accessed July 16, 2018.

OSRAM. 2011. Parathom CL A 40 Warm White DTC DIM BES. Material Declaration Sheet and RoHS Compliance

Declaration. 
https://www.osram.com/media/resource/HIRES/333052/94307/osram-material-declarationsheet_led.pdf. Accessed July 16, 2018.

OSRAM. 2016. OSRAM DULUX SUPERSTAR STICK. http://www.osram.de/osram_de/produkte/ lampen/kompaktleuchtstofflampen-mit-integriertem-vorschaltgeraet/osram-duluxsuperstar/osram-dulux-superstar-stick/index.jsp. Accessed August 30, 2016.

OVAM. 2006. Comparative LCA of 4 types of drinking cups used at events. https:// natureworksllc.com/ /media/Files/NatureWorks/What-is-Ingeo/Why-itMatters/LCA/OVAM_Cup_ComparativeLCA_FullReport_0206_pdf.pdf. Accessed July 16, 2018.

Pladerer, C., M. Meissner, F. Dinkel, M. Zschokke, G. Dehouse, and D. Schüler. Comparative Life Cycle Assessment of various Cup Systems for the Selling of Drinks at Events.

Quack, D. and M. Möller. 2005. Ökobilanzielle Analyse von Rechnung Online im Vergleich zu Rechnung per Brief. https://oeko.de/oekodoc/282/2005-019-de.pdf. Accessed October 21, 2016.

Sodastream. 2015. Personal communcation with Sodastream GmbH. June 16.

Stiel, F. and F. Teuteberg. 2013. Towards A Conceptual Framework For Life Cycle Assessment In Sustainable Information Systems Management. In ECIS 2013 Completed Research 91, 1-12.

Transfermarkt. 2018. Besucherzahlen. https://www.transfermarkt.de/1-bundesliga/besucherzahlen/ wettbewerb/L1/. Accessed April 24, 2018.

UBA. 2012. Daten zum Verkehr. https://umweltbundesamt.de/sites/default/files/medien/ publikation/long/4364.pdf. Accessed July 16, 2018.

VDM. 2016. Der Mineralwasser-Markt: Zahlen und Fakten 2016. https://mineralwasser. com/fileadmin/user_upload/VDM-Zahlen_Fakten_2016_WEB.pdf. Accessed July 16, 2018.

Vercalsteren, A., C. Spirinckx, and T. Geerken. 2010. Life cycle assessment and eco-efficiency analysis of drinking cups used at public events. The International Journal of Life Cycle Assessment 15(2): 221-230. http://link.springer.com/10.1007/s11367-009-0143-z. 